\title{
Análise acadêmica dos indicadores do global innovation index
}

\author{
Academic analysis of the indicators of the global innovation index \\ Análisis académico de los indicadores del índice global de innovación
}

\author{
Aldemir Freire Moreira \\ ORCID: https://orcid.org/0000-0002-7758-2892 \\ Universidade Estadual do Ceará, Brasil \\ aldemir.moreira@uece.br \\ Samuel Façanha Câmara \\ ORCID: https://orcid.org/0000-0002-8333-6997 \\ Universidade Estadual do Ceará, Brasil \\ samuel.camara@uece.br \\ Elda Fontinele Tahim \\ ORCID: https://orcid.org/0000-0002-4135-7714 \\ Universidade Estadual do Ceará, Brasil \\ elda.tahim@uece.br
}

\begin{abstract}
Resumo
Dada a importância da inovação no esforço de crescimento econômico das economias e a possibilidade de gerenciamento deste processo por parte dos governos, se faz necessário cada vez mais o aprimoramento de instrumentos que possibilitem a tomada de decisão por parte dos gestores. Estre estes, estão as indispensáveis métricas, já que não se consegue gerenciar o que não se pode mensurar. Dentro deste contexto, este trabalho busca verificar se há sustentação acadêmica para justificar a utilização dos específicos 80 (oitenta) indicadores que compõem a estrutura de construção de uma das mais importantes métricas do nível de inovação, nominada de Global Innovation Index - GII. Este objetivo é perseguido através de pesquisa bibliográfica extensa, mas não exaustiva, onde se conseguiu detectar na literatura científica no mínimo 2 (duas) publicações que justificam a seleção por parte dos construtores do GII - 2020 de cada um dos indicadores. Este resultado, de certa forma, complementa os resultados das auditorias externas independentes, realizadas anualmente, no cálculo dos indicadores e do índice deles composto no esforço de validação e geração de credibilidade na métrica.
\end{abstract}

Palavras-chave: Inovação; Métricas; Indicadores; Justificativa acadêmica.

\begin{abstract}
Given the importance of innovation in the economic growth effort of economies and the possibility of managing this process by governments, it is increasingly necessary to improve instruments that enable decision-making by managers. Among these are the indispensable metrics, since you cannot manage what you cannot measure. Within this context, this work seeks to verify if there is an academic support to justify the use of the specific 80 (eighty) indicators that make up the construction structure of one of the most important metrics of the level of innovation, called the Global Innovation Index - GII. This objective is pursued through extensive, but not exhaustive, bibliographic research, where it was possible to detect in the scientific literature at least 2 (two) publications that justify the selection by the builders of the GII - 2020 of each of the indicators. This result, in a way, complements the results of independent external audits, carried out annually, in the calculation of the indicators and their composite index in the effort to validate and generate credibility in the metric.
\end{abstract}

Keywords: Innovation; Metrics; Indicators; Academic justification.

\section{Resumen}

Dada la importancia de la innovación en el esfuerzo de crecimiento económico de las economías y la posibilidad de gestionar este proceso por parte de los gobiernos, se hace cada vez más necesario mejorar los instrumentos que permitan la toma de decisiones por parte de los gestores. Entre estas están las métricas indispensables, ya que no puedes gestionar lo que no puedes medir. En este contexto, este trabajo busca verificar si existe un sustento académico que justifique el uso de los 80 (ochenta) indicadores específicos que componen la estructura de construcción de una de las métricas más importantes del nivel de innovación, denominada Índice Global de Innovación. -GII. Este objetivo se persigue a través de una extensa, pero no exhaustiva, investigación bibliográfica, donde fue posible detectar en la literatura científica al menos 2 (dos) publicaciones que justifiquen la selección por parte de los constructores del GII 2020 de cada uno de los indicadores. Este resultado, en cierto modo, complementa los resultados de auditorías externas 
independientes, realizadas anualmente, en el cálculo de los indicadores y su índice compuesto en el esfuerzo por validar y generar credibilidad en la métrica.

Palabras clave: Innovación; Métrica; Indicadores; Justificación académica.

\section{Introdução}

A relação positiva entre inovação e crescimento econômico parece inquestionável (Pradhan et al., 2016; Schumpeter, 1997; Carlisle et al., 2006; Freeman, 1995; DOSI et al., 1988; Nelson et al., 1982). Essa relação é observada através de métricas que tentam mensurar o nível de inovação dos países. Entre estas merece destaque o Índice Global de Inovação (Global Innovation Index - GII). Este Índice é calculado com base em indicadores relacionados ao nível de crescimento econômico do país como qualidade e maturidade das instituições, transparência e estabilidade política, capital humano, infraestrutura e níveis tecnológico, dos mercados e dos negócios. Os indicadores permitem mensurar o GII para cada nação usando-se a metodologia desenvolvida pelo Professor Soumitra Dutta do Departamento Nacional das Indústrias da Índia (Amon-Há et al, 2019).

A relação acima referenciada pode ser comprovada pelo fato dos 22 (vinte e dois) países melhor posicionados no GII 2020 (dados de 2019), quais sejam, Suiça, Suécia, EUA, Inglaterra, Holanda, Dinamarca, Finlândia, Singapura, Alemanha, Coréia, Hong Kong, França, Israel, China, Irlanda, Japão, Canadá, Luxemburgo, Áustria, Noruega, Islândia e Bélgica figurarem entre os 22 países de maior renda per capita do mundo, exceções feitas para a China e Coréia do Sul, os quais não figuraram entre os países de maior renda per capita (FMI, 2019).

Dada a correlação entre a inovação e o crescimento econômico, parece acertado colocar a inovação no centro das estratégias de gestão dos governos nos dias de hoje. Vários estudos indicam ser possível melhorar o quadro da inovação através de políticas públicas direcionadas para este fim (Meyer et al., 1991; Barbieri et al., 2010; Boraha et al., 2014; Mazzucato, 2014; Efrat, 2014; Audy, 2017; Malikb et al., 2019).

\section{Metodologia}

O tipo de pesquisa utilizado foi a revisão integrativa da literatura já que se queria utilizar um método de pesquisa que permitisse a busca, a avaliação crítica e a síntese das evidências disponíveis do tema investigado, sendo o seu produto final o estado atual do conhecimento do tema investigado, bem como a identificação de lacunas que direcionassem para o desenvolvimento de futuras pesquisas (Roman et al., 1998; Broome, 2000; Coscrato, Pina et al., 2010). Desta forma, se buscou informações sobre o relacionamento entre os indicadores e o nível de inovação dos 131 (cento e trinta e um) países da amostra utilizada na elaboração do GII - 2020. Assim, foi possível corroborar (ou refutar) a pertinência do indicador na estrutura de construção do Índice.

Na revisão bibliográfica foram utilizados o Google Acadêmico e diversos sites de periódicos e autores alojados na internet. As buscas foram realizadas com a utilização de palavras-chave pertinentes a cada um dos 80 (oitenta) indicadores de inovação utilizados na elaboração do GII - 2020. Para cada indicador foram selecionados no mínimo duas publicações acadêmicas que indicaram haver relação deste com a inovação evidenciada através de citações, considerações e conclusões elaboradas pelos autores nos seus trabalhos.

\section{Resultados e Discussão}

Há uma frase comum nos manuais estudados nos cursos de Administração - "Não há controle sobre o que não se pode medir”. Esta afirmação indica haver a necessidade da utilização de métricas do nível da inovação que tragam informações indispensáveis para a tomada de decisão, supervisão e avaliação do processo de inovativo tanto no nível empresarial (micro) 
Research, Society and Development, v. 11, n. 3, e19911326092, 2022

(CC BY 4.0) | ISSN 2525-3409 | DOI: http://dx.doi.org/10.33448/rsd-v11i3.26092

como na sociedade (macro). Um desafio importante é encontrar métricas que capturem a inovação na forma que ela se concretiza na atualidade (OECD SCOREBOARD, 2013; WIPO, 2011). Medidas oficiais diretas que quantificam os resultados da inovação permanecem extremamente escassas. Por exemplo, não existem estatísticas oficiais sobre a quantidade de atividade inovadora - definida como o número de novos produtos, processos ou outras inovações - para qualquer ator de inovação, como o setor de serviços, ou entidades públicas ou qualquer país (Dutta et al., 2016, p. 38). Charmes, Gault e Wunsch-Vincent (2018) informam que a maioria das medições também têm dificuldade para capturar adequadamente os resultados da inovação de um amplo espectro de atores da inovação. Isso inclui pesquisas que muito têm contribuído para a medição das atividades de inovação, mas que falham em fornecer um bom e confiável desempenho do seu desenvolvimento em várias economias, e que muitas vezes não são aplicáveis às economias em desenvolvimento (onde a inovação é frequentemente informal).

Os índices de inovação no nível macroeconômico têm uma série de limitações colocadas para o uso pelos formuladores de políticas. A primeira delas é que estes índices não conseguem capturar rapidamente as variações nos modelos no nível das empresas (Hollanders \& Van Cruysen, 2008). Também, a capacidade de inovação utilizada em cada um dos índices não capturara suficientemente a complexidade da atividade inovativa (Saisana, 2004; Nardo et al., 2005). Outras críticas se referem ao fato das métricas focarem mais nos inputs que nos outputs; serem frequentemente atemporais devido a indisponibilidade e falta de maturidade dos dados; e, dadas medidas específicas, falham na captura da interação entre países, pois alguns deles tendem a ser fontes em inovação e outros apresentam menores contribuições (Hao et al., 2017).

A métrica estudada neste trabalho é o Global Innovation Index de 2020 (GII 2020). O projeto deste Índice foi lançado pelo Professor Soumitra Dutta em 2007 durante sua gestão no INSEAD (Institut Européen d'Administration des Affaires). O Índice conta com uma estrutura composta de 80 (oitenta) indicadores pesquisados em 131 (cento e trinta e um) países conforme publicação do ano de 2020 (GII, 2020). O detalhamento dos indicadores e seus escores são divulgados anualmente desde 2011 pelo "consórcio" formado pela University of Cornell - SC Johnson College of Business, World Intelectual Property Organization - WIPO e pelo Institut Européen d'Administration des Affaires - INSEAD. A amostra dos países que integram o GII 2020 representa adequadamente o universo que o representa, pois a amostra contem 93,5\% da população e 97,4\% do PIB mundial em dólares internacionais correntes na paridade de poder de compra.

O objetivo da confecção do Índice era encontrar métricas e métodos que melhor capturassem a riqueza da inovação na sociedade, indo além das medidas tradicionais, como o número e nível de artigos de pesquisa e os gastos com pesquisa e desenvolvimento (GII, 2011). O GII é um projeto em evolução que se baseia em suas edições anteriores, enquanto incorpora dados e pesquisas mais recentes sobre a medição da inovação (GII, 2020).

No GII, os fatores de inovação estão sob avaliação contínua. Isto fornece uma ferramenta fundamental para os tomadores de decisão e um rico banco de dados de métricas detalhadas para refinar as políticas de inovação.

O GII não pretende ser a classificação final e definitiva das economias no que diz respeito à inovação. Medir os resultados da inovação e seu impacto permanecem difíceis. Os elaboradores do Índice dão grande ênfase a medição do clima e infraestrutura para a inovação, a avaliação dos resultados relacionados, a busca de melhor medição, a melhor compreensão da inovação e a identificação de políticas que promovam a inovação (Dutta et al., 2020).

Os dados utilizados no GII 2020 foram selecionados da seguinte forma: 29,9\% dos dados obtidos são de 2019; 41,5\% de 2018; $10,7 \%$ de 2017; 3,6\% de 2016; 1,6\% de 2015, e o restante de 3,1\%, são dos anos anteriores (GII 2020).

O GII presta atenção especial em apresentar a posição dos diversos componentes para cada economia, seleciona pontos fortes e fracos, suas definições e respectivas fontes, notas técnicas detalhadas e ajustes na estrutura GII. Além disso, desde seu início, o GII passa por um processo de auditoria estatística independente realizada pelo European Union Joint Research Center, o que dá mais sustentação ao instrumento (GII, 2020, apêndices II, III, IV e V, p. 211-386). 
Embora os autores do GII reconheçam a limitação da definição para uso apenas na medição estatística no setor empresarial e se esquecem das inovações no setor público e no setor das famílias, a definição de inovação utilizada para a elaboração do Índice é a originalmente elaborada a partir do Manual de Oslo de 2005, onde é introduzida uma série de definições associadas à inovação nas atividades empresariais e em diferentes tipos de empresas (Gault, 2018).

Nas últimas duas décadas, economistas e formuladores de políticas focavam em R\&D baseada em inovação tecnológica de produtos, amplamente produzida internamente e, principalmente, nas indústrias de manufatura. As inovações desta natureza foram executadas por uma força de trabalho altamente qualificada em empresas intensivas em P\&D, em um processo de inovação caracterizado como fechado, interno e localizado. Os avanços tecnológicos eram os reconhecidos como "radicais" e que ocorriam na "fronteira global do conhecimento". Esta caracterização implicava a existência de economias líderes e atrasadas com baixa ou média renda apenas realizando "catch up" (OECD, 2010; WIPO, 2011).

Cada vez mais a inovação enfoca a capacidade de explorar novas combinações tecnológicas, a inovação incremental e a "inovação sem pesquisa". Há um interesse constante na compreensão de como a inovação evolui nas economias de baixa e média renda e na conscientização de que as suas formas incrementais podem impactar o desenvolvimento. Além disso, o próprio processo de inovação mudou significativamente. O investimento em atividades relacionadas à inovação tem sido consistentemente intensificado nas empresas e na economia em nível global, adicionando dois novos atores de inovação: aqueles fora das economias de alta renda e os atores sem fins lucrativos. Além disso, a estrutura do conhecimento é mais complexa e a atividade de produção geograficamente mais dispersa (GII, 2020).

Para que se possa analisar os dados produzidos pelo GII 2020, se faz necessário conhecer inicialmente como estão estruturados e o significado de cada um dos indicadores utilizados. A estrutura do GII 2020 é alicerçada em dois subíndices: Subíndice de Insumos de Inovação e Subíndice de Produção de Inovação. O Subíndice de Insumos de Inovação é composto por cinco pilares que tentam capturar os elementos da economia nacional que possibilitam a atividade inovativa. O Subíndice de Produção de Inovação se refere aos resultados das atividades inovadoras na economia. Embora o subíndice de saída inclua apenas dois pilares, tem o mesmo peso no cálculo do GII que o subíndice de entrada. A pontuação geral do GII é a média simples dos dois subíndices. O Subíndice de Insumos de Inovação é composto de 5 (cinco) pilares e o Subíndice de Produção de Inovação, 2 (dois) pilares. Cada pilar, por sua vez, é dividido em três subpilares, cada um dos quais, composto de 2 (dois) a 5 (cinco) indicadores em um total de 80 (oitenta) no GII 2020.

Os cinco pilares capacitadores que compõem o primeiro subíndice definem aspectos do ambiente propício à inovação dentro de uma economia: (1) instituições, (2) capital humano e pesquisa, (3) infraestrutura, (4) sofisticação de mercado e (5) sofisticação empresarial. Os pilares relacionados à produção são (6) produtos de conhecimento e tecnologia e (7) resultados criativos.

O pilar Instituições tenta capturar a estrutura institucional de uma economia, mensurando a capacidade que a estrutura institucional tem em atrair negócios e promover o crescimento, fornecendo boa governança e corretos níveis de proteção e incentivos essenciais para a inovação. Assim tenta mensurar os ambientes político, regulatório e de negócios. É composto dos três seguintes subpilares: (1.1) - “Ambiente político", (1.2) - “Ambiente regulatório" e (1.3) - “Ambiente de negócios".

O segundo pilar, (2) "capital humano e pesquisa", tenta aferir o nível e padrão de educação em atividades de pesquisa em uma economia, já que são os principais determinantes da capacidade de inovação de uma nação. É composto dos subpilares (2.1) educação", (2.2) “ensino superior” e (2.3) "pesquisa e desenvolvimento (P\&D)".

O terceiro pilar, (3) - "infraestrutura" inclui três subpilares: 3.1 "tecnologia da informação e da comunicação (TICs)", 3.2 “infraestrutura geral” e 3.3 "sustentabilidade ecológica". Estes subpilares visam verificar de forma mais ampla a qualidade e o acesso à comunicação, transportes (inclusive quanto ao item “ecologicamente correto") e infraestrutura de energia elétrica, fatores que facilitam a troca de ideias na produção de bens e serviços e alimentam o sistema de inovação por meio de maior 
produtividade e eficiência, com menores custos de transação e melhor acesso aos mercados e com crescimento sustentável.

O pilar "sofisticação do mercado" (4) avalia a disponibilidade de crédito e o ambiente que apoie o investimento, o acesso ao mercado internacional, a competição e a escala do mercado, fundamentais para que a inovação ocorra. Este pilar é composto de três subpilares estruturados em torno das condições de mercado e do total nível de transações: (4.1) "crédito", (4.2) "investimentos" e (4.3) - "comércio, concorrência e escala do mercado".

O último pilar dentro do "Subíndice de Insumos para a Inovação" é a (5) "sofisticação de negócios". Este pilar tenta avaliar o quão propícias as empresas estão na atividade inovativa. Como se verificou no segundo pilar, a acumulação de capital humano em todos os níveis através da educação e a priorização das atividades em P\&D são condições indispensáveis para que a inovação se desenvolva. Essa lógica é levada um passo adiante aqui com a afirmação de que as empresas estimulam sua produtividade, competitividade e potencial de inovação com a contratação de profissionais altamente qualificados tecnicamente. É composto dos seguintes subpilares: (5.1) - "Profissionais do conhecimento", (5.2) - "vínculos para fins de inovação" e (5.3) "Absorção de conhecimentos".

O segundo componente do GII 2020 é o Subíndice de Produção de Inovação, o qual corresponde ao resultado das atividades inovadoras dentro de uma economia. É composto de dois pilares: (6) "Produtos de conhecimento e tecnologia" e (7) "Resultados criativos".

O primeiro pilar cobre todas as variáveis que são tradicionalmente consideradas frutos de invenções e/ou inovações tem como subpilares: (6.1) - "Criação de conhecimento", (6.2) - "impacto no conhecimento" e (6.3) "difusão do conhecimento".

O sétimo e último pilar se refere aos resultados da criatividade. Como se sabe o papel da criatividade para a inovação ainda é amplamente subestimado nos debates sobre políticas de inovação e a sua medição (GII, 2020). Desde o seu início, o GII sempre enfatizou medir a criatividade como parte de seu subíndice de produção de inovação. Este pilar é composto de três subpilares: (7.1) - "ativos intangíveis", (7.2) - "Produtos Criativos e (7.3) - "Criatividade online".

Expomos na Quadro 1, abaixo, a descrição de cada um dos indicadores e a seleção de pelo menos duas referências bibliográficas que justificam a sua relação com a inovação. Esta pesquisa bibliográfica no entanto, não é exaustiva. Parte das relações apontadas pelos autores não é clara ou conflitante em termos de direção da relação.

Quadro 1: Descrição dos indicadores do GII 2020 e suas justificativas acadêmicas de relação com a inovação.

\begin{tabular}{|c|c|c|c|c|}
\hline \multicolumn{2}{|c|}{ Indicadores } & \multirow[b]{2}{*}{\begin{tabular}{|l} 
Descrição \\
Mensura o risco \\
político, legal, \\
operacional ou de \\
segurança que possam \\
afetar negócios e \\
operações.
\end{tabular}} & \multirow{2}{*}{$\begin{array}{l}\text { Referência } \\
\text { 1. Allard et al. } \\
\text { (2012); } 2 . \\
\text { Abeyasinghe \& } \\
\text { Seeborg (2004) }\end{array}$} & \multirow{2}{*}{$\begin{array}{l}\text { Conclusões } \\
\text { 1. "... a instabilidade política de um país impacta negativamente seu sistema nacional } \\
\text { de inovação"; } 2 . \text { "... apresenta impacto significativo no crescimento econômico, } \\
\text { embora não aconteça o mesmo com a democracia". }\end{array}$} \\
\hline 1.1.1 & \begin{tabular}{|l} 
Estabil. \\
polít. / \\
operacion \\
al
\end{tabular} & & & \\
\hline 1.1 .2 & $\begin{array}{l}\text { Eficácia } \\
\text { do } \\
\text { governo }\end{array}$ & $\begin{array}{l}\text { Percepção da } \\
\text { qualidade dos } \\
\text { serviços/políticas } \\
\text { públicas, sua } \\
\text { implementação, } \\
\text { credibilidade do } \\
\text { compromisso c/ elas e } \\
\text { o grau de } \\
\text { independência do } \\
\text { governo frente } \\
\text { pressões políticas. }\end{array}$ & $\begin{array}{l}\text { 1. Jiao et al. } \\
\text { (2015); } 2 . \\
\text { Rodríguez-Pose e } \\
\text { Cataldo (2015); } 3 . \\
\text { Wen et al. (2021); } \\
\text { 4. Oluwatobi et al. } \\
\text { (2014). }\end{array}$ & $\begin{array}{l}\text { 1. "... a eficácia do governo tem um efeito significativamente positivo na inovação } \\
\text { em produtos, tecnológica, de processos e de gestão."; } 2 . \text { "... encontraram fortes } \\
\text { evidências de robusta ligação entre a qualidade do governo e a capacidade de } \\
\text { inovação na UE e que os governos ineficazes e corruptos representam uma barreira } \\
\text { fundamental à capacidade inovadora, minando fortemente qualquer efeito potencial } \\
\text { de quaisquer outras medidas destinadas a promover uma maior inovação."; } 3 . \text { "... } \\
\text { concluem que a eficácia do governo tem impacto significativamente positivo na } \\
\text { produção de inovação."; } 4 . \text { "... a eficácia do governo e a qualidade regulatória são } \\
\text { duas medidas institucionais que têm impacto positivo s/ a inovação." }\end{array}$ \\
\hline
\end{tabular}




\begin{tabular}{|c|c|c|c|c|}
\hline 1.2 .1 & $\begin{array}{l}\text { Qualidade } \\
\text { regulatóri } \\
\text { a }\end{array}$ & $\begin{array}{l}\text { Percepções da } \\
\text { capacidade normativa } \\
\text { do governo para } \\
\text { formular e } \\
\text { implementar políticas } \\
\text { sólidas que permitem } \\
\text { e promovam o } \\
\text { desenvolvimento do } \\
\text { setor privado }\end{array}$ & $\begin{array}{l}\text { 1. Mattos \& Abdal } \\
(2010) ; 2 . \text { Moreira } \\
\text { et al. (2007). }\end{array}$ & $\begin{array}{l}\text { 1. A implementação de um ambiente regulatório adequado e seu aperfeiçoamento } \\
\text { constitui o fundamento das políticas e das iniciativas de mobilização destinadas ao } \\
\text { estímulo ao empreendedorismo, à cooperação econômica e à redução de riscos para } \\
\text { investimentos em P\&D. Sem um ambiente regulatório e qualquer iniciativa de } \\
\text { mobilização e envolvimento do empresariado e da sociedade nos processos de } \\
\text { inovação não se permite ter resultados substanciais e de longo prazo; 2. Houve } \\
\text { avanços relevantes na regulação (e no financiamento) da C\&T no Brasil, mas que se } \\
\text { faz necessária a intensificação de ações a fim de permitir ao País deixar de ser um } \\
\text { mero coadjuvante no contexto dos países desenvolvidos. }\end{array}$ \\
\hline 1.2 .2 & $\begin{array}{l}\text { Estado de } \\
\text { direito }\end{array}$ & $\begin{array}{l}\text { Avaliação dos agentes } \\
\text { quanto a qualidade na } \\
\text { execução dos } \\
\text { contratos, o respeito } \\
\text { aos direitos de } \\
\text { propriedade, à polícia, } \\
\text { aos tribunais e a } \\
\text { ocorrência de crimes e } \\
\text { violência. }\end{array}$ & $\begin{array}{l}\text { 1. Rodríguez-Pose } \\
\text { \& Zhang (2020); } \\
\text { 2.Chadee e Roxas } \\
\text { (2013). }\end{array}$ & $\begin{array}{l}\text { 1. "... estes indicadores afetam tanto a probabilidade de ocorrência de inovação como } \\
\text { a sua intensidade nas empresas. Os resultados das análises econométricas mostram } \\
\text { que a baixa qualidade institucional na China urbana é uma barreira importante para a } \\
\text { inovação no nível empresarial. Em particular, um estado de direito deficiente com } \\
\text { alta corrupção e qualidade regulatória fraca prejudicam fortemente o nível de } \\
\text { inovação privada."; } 2 \text {. "... a qualidade regulatória, o estado de direito e a corrupção } \\
\text { têm fortes impactos diretos e negativos sobre a capacidade de inovação e o } \\
\text { desempenho das empresas. Os resultados sugerem que o estado atual da qualidade } \\
\text { regulatória, estado de direito e corrupção na Rússia inibe a inovação das empresas e } \\
\text { seu desempenho. }\end{array}$ \\
\hline 1.2 .3 & $\begin{array}{l}\text { Custo } \\
\text { demissão, } \\
\text { sem. sal. }\end{array}$ & $\begin{array}{l}\text { Custo das demissões } \\
\text { de um trabalhador: } \\
\text { custo do aviso prévio } \\
\text { e indenizações devidas } \\
\text { quando da recisão de } \\
\text { contrato de trabalho, } \\
\text { expresso em semanas } \\
\text { de salário, valor médio } \\
\text { dos requisitos de } \\
\text { notificação e } \\
\text { indenizações } \\
\text { aplicáveis a um } \\
\text { trabalhador com } 1,5 \text { e } \\
10 \text { anos. }\end{array}$ & $\begin{array}{l}\text { 1. Acharya, } \\
\text { Baghai, \& } \\
\text { Subramanian } \\
\text { (2013); 2. Griffith } \\
\text { \& Macartney } \\
\text { (2014). }\end{array}$ & $\begin{array}{l}\text { 1. "Quando os contratos estão incompletos, as leis de demissão impedem os } \\
\text { empregadores de dispensar arbitrariamente os funcionários e, portanto, limitam a } \\
\text { capacidade dos empregadores de manter funcionários inovadores depois que uma } \\
\text { inovação é bem-sucedida. As leis de demissão podem melhorar os esforços } \\
\text { inovadores dos funcionários e incentivar as empresas a investirem em projetos } \\
\text { arriscados, mas potencialmente inovadores. Outras formas de leis trabalhistas que } \\
\text { não afetam a demissão de funcionários não têm esse lado positivo. Leis de demissão } \\
\text { mais rigorosas estimulam a inovação, especialmente em setores de inovação } \\
\text { intensiva, mas outras leis trabalhistas não"; 2. "...os efeitos teóricos das } \\
\text { regulamentações trabalhistas, como a legislação de proteção ao emprego } \\
\text { (Employment Protection Law - EPL), sobre a inovação são ambíguos. A EPL } \\
\text { aumenta a segurança no emprego e a maior aplicabilidade dos contratos de trabalho o } \\
\text { que contribui para o aumento do investimento do trabalhador em atividades } \\
\text { inovadoras. Por outro lado, a EPL aumenta os custos de ajuste das empresas, o que } \\
\text { pode levar a um sub-investimento em atividades que provavelmente exigirão ajustes, } \\
\text { incluindo inovação tecnologicamente avançada." }\end{array}$ \\
\hline 1.3 .1 & $\begin{array}{l}\text { Facilidade } \\
\text { p/ abrir } \\
\text { empresa }\end{array}$ & $\begin{array}{l}\text { Captura a duração } \\
\text { mediana necessária } \\
\text { para concluir um } \\
\text { procedimento de } \\
\text { criação de um } \\
\text { negócio. }\end{array}$ & $\begin{array}{l}\text { 1. Conhen (2008); } \\
\text { 2. Thompson } \\
(1965) ; 3 \text {. } \\
\text { Menezes et al. } \\
(2014) \text {. }\end{array}$ & $\begin{array}{l}\text { 1. "... a maioria das organizações burocráticas não são conhecidas pela sua } \\
\text { capacidade de encorajar a geração de novas ideias e experimentações."; 2. "... já } \\
\text { alertava que a constante busca por produtividade e controle proporcionado pela } \\
\text { burocracia se mostra inadequada ao florescimento e crescimento da criatividade. "; } \\
\text { 3. "... propõe que, para aumentar a taxa de inovação no Brasil, entre outras } \\
\text { sugestões, o governo deveria diminuir a burocracia para abertura de novas firmas." }\end{array}$ \\
\hline 1.3.2 & $\begin{array}{l}\text { Facil } \\
\text { resolução } \\
\text { insolvênci } \\
\text { a }\end{array}$ & $\begin{array}{l}\text { Taxa média do valor } \\
\text { recuperado c/ } \\
\text { garantias pela } \\
\text { reorganização, } \\
\text { liquidação ou } \\
\text { execução. }\end{array}$ & $\begin{array}{l}\text { 1. Saltane, Chen } \\
\text { \& Guzman } \\
(2013) ; 2 . \\
\text { Bhargava (2019, } \\
\text { p. 473) }\end{array}$ & $\begin{array}{l}\text { 1. Governos em todo o mundo implementaram extensas reformas com o objetivo de } \\
\text { fortalecer os mecanismos regulatórios para solucionar casos de insolvência, } \\
\text { estimular o empreendedorismo e gerar alocação mais eficiente de recursos de } \\
\text { mercado; 2. O governo indiano apresenta ainda falhas importantes, como a } \\
\text { dificuldade de resolução de insolvência. }\end{array}$ \\
\hline 2.1.1 & $\begin{array}{l}\text { Gastos c/ } \\
\text { educação } \\
\% \text { PIB }\end{array}$ & $\begin{array}{l}\text { Despesas do governo } \\
\text { com educação em } \\
\text { qualquer nível, } \\
\text { expresso em \% do } \\
\text { PIB, inclusive } \\
\text { financiamentos } \\
\text { internacionais. }\end{array}$ & $\begin{array}{l}\text { 1. Tomás (2011); } \\
\text { 2. Pegkas, } \\
\text { Staikouras \& } \\
\text { Tsamadias (2019). }\end{array}$ & $\begin{array}{l}\text { 1. "... as despesas com educação conduzem positivamente a competitividade nacional } \\
\text { e a inovação."; } 2 \text {. "Os resultados revelam a existência de um efeito positivo e } \\
\text { significativo da P\&D empresarial, pública e do ensino superior na inovação. A P\&D } \\
\text { empresarial é o setor com maior efeito positivo sobre a inovação. Os resultados } \\
\text { indicam que a UE deve reforçar a cooperação entre as empresas, a P\&D do ensino } \\
\text { público e ensino superior, através do incentivo de parcerias entre o sector privado, a } \\
\text { P\&D e o sistema de inovação. }\end{array}$ \\
\hline
\end{tabular}




\begin{tabular}{|c|c|c|c|c|}
\hline 2.1 .2 & $\begin{array}{l}\text { Gasto } \\
\text { governam } \\
\text { ental por } \\
\text { aluno }\end{array}$ & $\begin{array}{l}\text { Gastos correntes e de } \\
\text { capital em qualquer } \\
\text { nível de governo em } \\
\text { financiamento para a } \\
\text { educação inicial p/ } \\
\text { aluno e inclui } \\
\text { transferências pagas, } \\
\text { mas exclui } \\
\text { transferências } \\
\text { internacionais. }\end{array}$ & $\begin{array}{l}\text { 1. Ramos (2010); } \\
\text { 2. Lunardi (2014). }\end{array}$ & $\begin{array}{l}\text { 1. "Considerando o que fizeram os países que estão ocupando um lugar de destaque } \\
\text { em P\&D e inovação, o Brasil precisa rapidamente enfrentar o desafio da qualidade } \\
\text { da educação básica, caso queira ser protagonista num cenário próximo da economia } \\
\text { mundial"; } 2 . \text { "... os resultados dos investimentos em educação no Brasil dão suporte à } \\
\text { hipótese de que políticas públicas com foco na expansão de investimentos em } \\
\text { educação impactariam positivamente no crescimento econômico do Brasil. O estudo } \\
\text { identificou que essa relação se deve ao aumento das parcelas da população } \\
\text { economicamente ativa com ensino primário, secundário ou terciário completo, } \\
\text { decorrente do aumento dos gastos públicos com educação. }\end{array}$ \\
\hline 2.1.3 & $\begin{array}{l}\text { Expectati } \\
\text { va de vida } \\
\text { escolar }\end{array}$ & $\begin{array}{l}\text { Anos de escolaridade } \\
\text { que uma criança de } \\
\text { certa idade pode } \\
\text { esperar receber no } \\
\text { futuro, assumindo a } \\
\text { probabilidade de ser } \\
\text { matriculada na escola } \\
\text { em qualquer idade de } \\
\text { ser igual à taxa de } \\
\text { matrícula atual. }\end{array}$ & $\begin{array}{l}\text { 1. Hovne, Hovne } \\
\text { \& Schott (2014); } \\
\text { 2. Kuenzer et al. } \\
\text { (2007). }\end{array}$ & $\begin{array}{l}\text { 1. "A capacidade de inovação dos empresários se beneficia da educação, } \\
\text { especialmente, do treinamento durante a escolaridade e também do treinamento após } \\
\text { a formatura. A inovação também é promovida por meio de políticas públicas de } \\
\text { apoio ao empreendedorismo. Uma cultura que enfatiza o individualismo } \\
\text { empreendedor modera o benefício na medida em que amplifica o benefício da } \\
\text { educação para a inovação."; } 2 \text {. "A inovação impõe reorganização da qualificação da } \\
\text { força de trabalho, considerando o uso intensivo de tecnologia microeletrônica dos } \\
\text { novos equipamentos e a demanda de conhecimentos científicos por parte dos } \\
\text { operadores. Constata também que os conhecimentos relativos à educação formal dos } \\
\text { trabalhadores, quando converge com as exigências das atividades executadas por } \\
\text { eles, tendem a facilitar a articulação dos conhecimentos tácitos e científicos . }\end{array}$ \\
\hline 2.1 .4 & $\begin{array}{l}\text { Escala } \\
\text { PISA }\end{array}$ & $\begin{array}{l}\text { Avaliação destinada } \\
\text { aos alunos do ensino } \\
\text { médio. }\end{array}$ & $\begin{array}{l}\text { 1. Ramos (2010); } \\
\text { 2. Menezes Filho } \\
\text { et al. (2014). }\end{array}$ & $\begin{array}{l}\text { 1. A melhoria da qualidade do ensino tem um imenso potencial para estimular a } \\
\text { inovação. } 2 \text {. O Brasil tem carência de capital humano adequado ao esforço } \\
\text { necessário para catapultar a inovação. A educação no Brasil tem pouca qualidade, } \\
\text { além da insuficiente quantidade de egressos das áreas científicas". }\end{array}$ \\
\hline 2.1 .5 & $\begin{array}{l}\text { Razão } \\
\text { aluno/prof } \\
\text {. no } \\
\text { ensino } \\
\text { médio }\end{array}$ & $\begin{array}{l}\mathrm{N}^{\circ} \text { de alunos } \\
\text { matriculados na escola } \\
\text { secundária dividido } \\
\text { pelo número de } \\
\text { professores do ensino } \\
\text { médio, independente } \\
\text { de sua atribuição de } \\
\text { ensino. }\end{array}$ & $\begin{array}{l}\text { 1. Bratsberg e } \\
\text { Terrel (2002); } 2 \\
\text { Tsaurai (2015); } 3 \\
\text { Chen \& Moul } \\
(2014) " ; \text {. } \\
\text { Asongu, Boateng, } \\
\text { \& Akamavi } \\
\text { (2016). }\end{array}$ & $\begin{array}{l}\text { 1. A proporção aluno-professor tem uma correlação ou associação negativa com } \\
\text { algumas variáveis, entre elas, as educacionais e socioeconômicas. Um alto valor da } \\
\text { proporção aluno-professor conduz a baixos retornos na educação; } 2 \text {. Indica diminuir } \\
\text { os investimentos estrangeiros diretos - IDE"; } 3 \text {. Diminui a produtividade industrial; } \\
\text { 4. A alta proporção aluno/professor exerce uma influência negativa no } \\
\text { desenvolvimento humano nos } 49 \text { países da África Subsaariana, independentemente } \\
\text { do nível de renda, origens legais, orientação religiosa e estado da nação. }\end{array}$ \\
\hline 2.2 .1 & $\begin{array}{l}\text { Matrícula } \\
\text { s no } \\
\text { ensino } \\
\text { superior }\end{array}$ & $\begin{array}{l}\text { \% de matrículas no } \\
\text { ensino superior, para a } \\
\text { população da faixa } \\
\text { etária correspondente } \\
\text { ao nível superior de } \\
\text { educação. }\end{array}$ & $\begin{array}{l}\text { 1. Mthembu } \\
\text { (2015); } 2 \text {. } \\
\text { Delgado \& Pessoa } \\
\text { (2010). }\end{array}$ & $\begin{array}{l}\text { 1. "... se sugere a existência de uma relação de cointegração de longo prazo entre } \\
\text { crescimento econômico, trabalho, capital, matrículas, despesas e inovação que é } \\
\text { consistente com a teoria econômica e que têm um impacto estatisticamente positivo } \\
\text { no crescimento econômico."; } 2 \text {. Há um papel estratégico imputado à Educação } \\
\text { Superior na sua relação com o fenômeno da mudança técnica no cenário em que a } \\
\text { geração de vantagens competitivas via progresso tecnológico tornou-se um télos da } \\
\text { Indústria brasileira, ávida em alçar a posição de país industrial exportador e } \\
\text { proficiente em inovação." }\end{array}$ \\
\hline 2.2.2 & $\begin{array}{l}\text { Graduado } \\
\text { s ciência e } \\
\text { engenhari } \\
\text { a }\end{array}$ & $\begin{array}{l}\text { Quantitativo dos } \\
\text { graduados em ciências } \\
\text { naturais, matemática, } \\
\text { estatística, informação } \\
\text { e tecnologia e } \\
\text { engenharia como \% } \\
\text { dos graduados de } \\
\text { nível superior }\end{array}$ & $\begin{array}{l}\text { 1. Rodriguez-Pose } \\
\text { \& Lee (2020); } 2 \text {. } \\
\text { Atkinson \& Mayo } \\
\text { (2010). }\end{array}$ & $\begin{array}{l}\text { 1. "A inovação nas cidades é cada vez mais considerada o resultado da atividade } \\
\text { científica e criatividade ... embora à primeira vista a presença de trabalhadores } \\
\text { egressos dos cursos de ciências, engenharia e matemática sejam um motor de } \\
\text { inovação mais importante do que o criativo, é a combinação de ambos os fatores que } \\
\text { maximiza a inovação nas cidades americanas."; } 2 \text {. "... concluem que a participação } \\
\text { dos EUA nas indústrias baseadas em inovação está em declínio, colocando em risco } \\
\text { o seu status de liderança em inovação e que, um dos motivos, é que os EUA não } \\
\text { conseguiram produzir trabalhadores próprios em número suficiente com habilidades } \\
\text { suficientes em ciência, tecnologia, engenharia e matemática." }\end{array}$ \\
\hline
\end{tabular}




\begin{tabular}{|c|c|c|c|c|}
\hline 2.2 .3 & $\begin{array}{l}\text { Mobilidad } \\
\text { e ensino } \\
\text { superior }\end{array}$ & $\begin{array}{l}\text { Número de alunos que } \\
\text { estudam no exterior } \\
\text { como uma } \\
\text { porcentagem do total } \\
\text { de matrículas no nível } \\
\text { superior no país. }\end{array}$ & $\begin{array}{l}\text { 1. Siekierski } \\
\text { (2018); } 2 . \\
\text { Siekierski, Lima } \\
\text { \& Borini (2019); } \\
\text { 3. Vincent- } \\
\text { Lancein (2004); } 4 . \\
\text { Arif (2017). }\end{array}$ & $\begin{array}{l}\text { 1. A mobilidade acadêmica internacional gera inovação através do desenvolvimento } \\
\text { de redes de pesquisa e a geração de parcerias entre universidades, indústrias e } \\
\text { laboratórios que podem trazer melhorias à educação e a ciência; } 2 \text {. Há uma relação } \\
\text { positiva entre a mobilidade acadêmica internacional e a inovação. Os efeitos } \\
\text { positivos dessa relação beneficiam os países de destino e de origem; 3. As estratégias } \\
\text { de importação deliberada de educação transfronteiriça podem ser uma boa } \\
\text { ferramenta para as economias em desenvolvimento no sentido de melhorar a } \\
\text { qualidade e a quantidade do capital humano; } 4 \text {. Na relação entre mobilidade de } \\
\text { estudantes internacionais e difusão de tecnologia, a educação estrangeira tem um } \\
\text { efeito estatisticamente significativo na difusão de tecnologia. }\end{array}$ \\
\hline 2.3 .1 & $\begin{array}{l}\text { Pesquisad } \\
\text { ores em } \\
\text { Equivalên } \\
\text { cia em } \\
\text { Tempo } \\
\text { Integral } \\
\text { (Eti)-mi. } \\
\text { Hab }\end{array}$ & $\begin{array}{l}\text { Pesquisadores em } \\
\text { equivalência de tempo } \\
\text { integral p/ milhão de } \\
\text { hab. envolvidos na } \\
\text { criação de novos } \\
\text { conhecimentos, } \\
\text { produtos, processos, } \\
\text { métodos, ou sistemas } \\
\text { e na gestão dos } \\
\text { projetos, inclusos os } \\
\text { alunos de pós- } \\
\text { graduação engajados. }\end{array}$ & $\begin{array}{l}\text { 1. Rocha \& } \\
\text { Ferreira (2004); } 2 . \\
\text { Velho (2997). }\end{array}$ & $\begin{array}{l}\text { 1. "... utilizaram mensuradores para avaliar o nível da C,T\&I nos estados federativos } \\
\text { brasileiros. Uma das métricas é Pesquisadores por milhão de habitantes: número de } \\
\text { pesquisadores por grupo de milhão de habitantes do estado, no ano 2000.”; } 2 \text {. "... as } \\
\text { universidades produzem profissionais e pesquisadores qualificados. Estes, ao serem } \\
\text { incorporados pelas empresas e outros setores da sociedade, levam consigo não } \\
\text { apenas conhecimento científico recente, mas também habilidades para resolver } \\
\text { problemas complexos, realizar pesquisa e desenvolver novas ideias. Esse pessoal } \\
\text { possui também habilidade tácita para adquirir e usar conhecimento de maneira } \\
\text { inovadora, além de deter o que alguns autores chamam de "conhecimento do } \\
\text { conhecimento", ou seja, sabem quem sabe o que, pois participam das redes } \\
\text { acadêmicas e profissionais no nível nacional e internacional. Quando se engajam em } \\
\text { atividades fora do meio acadêmico, os profissionais e pesquisadores tendem a } \\
\text { imprimir em tais contextos uma nova atitude mental e espírito crítico que favorecem } \\
\text { as atividades inovativas." }\end{array}$ \\
\hline 2.3 .2 & $\begin{array}{l}\text { Gastos } \\
\text { brutos } \\
\text { com P\&D }\end{array}$ & $\begin{array}{l}\text { Gastos com P\&D } \\
\text { realizados dentro de } \\
\text { uma unidade } \\
\text { estatística ou setor da } \\
\text { economia durante } \\
\text { período específico, } \\
\text { qualquer que seja a } \\
\text { origem. }\end{array}$ & $\begin{array}{l}\text { 1. Pelikánová } \\
\text { (2019); } 2 . \\
\text { Akinwale (2012). }\end{array}$ & $\begin{array}{l}\text { 1. A EU tomou como sua estratégia (Europa 2020) que 3\% do PIB deve ser alocado } \\
\text { para P\&D o que deve aumentar os níveis de inovação e tornar a UE uma líder na } \\
\text { economia mundial; } 2 \text {. A produtividade total do fator responsável pela proporção de } \\
\text { crescimento econômico que não é capturado por insumos de trabalho e capital é } \\
\text { mensurada por P\&D e inovação. Na Nigéria, usando o método dos mínimos } \\
\text { quadrados, o resultado dos } 31 \text { (trinta e um) anos (1977-2007) revisados mostra que a } \\
\text { GERD (Gross Expenditure in R\&D) tem impacto significativo no crescimento } \\
\text { econômico. }\end{array}$ \\
\hline 2.3 .3 & $\begin{array}{l}\text { Empresas } \\
\text { globais de } \\
\text { P\&D }\end{array}$ & $\begin{array}{l}\text { Gastos médios das } 3 \\
\text { principais empresas } \\
\text { globais de P\&D em } \\
\text { US\$ milhões. }\end{array}$ & $\begin{array}{l}\text { 1. Ferraris at al. } \\
\text { (2019); 2. Queiroz } \\
\text { \& Carvalho } \\
\text { (2005). }\end{array}$ & $\begin{array}{l}\text { 1. "... argumenta que o número de parcerias globais de P\&D tem crescido nos } \\
\text { últimos tempos graças à riqueza de conhecimentos e habilidades interculturais que } \\
\text { fornecem às empresas, permitindo as empresas diferenciar significativamente seus } \\
\text { processos de inovação e atualizar seu desempenho na inovação." 2. "... o } \\
\text { engajamento atual e potencial das empresas multinacionais em atividades } \\
\text { tecnológicas no Brasil. Argumenta que a maior propensão dessas empresas em } \\
\text { realizar atividades de pesquisa e desenvolvimento (P\&D) fora de seus países de } \\
\text { origem pode representar uma oportunidade para reforçar o sistema nacional de } \\
\text { inovação." }\end{array}$ \\
\hline 2.3 .4 & $\begin{array}{l}\text { Ranking } \\
\text { univ. da } \\
\text { QS }\end{array}$ & $\begin{array}{l}\text { A classificação de } \\
\text { universidades } \\
\text { calculada pelas } \\
\text { pontuações médias das } \\
\text { três melhores do país } \\
\text { que pertencem às } \\
\text { melhores } 700 \text { em todo } \\
\text { o mundo }\end{array}$ & $\begin{array}{l}\text { 1. Zosa (2013); } 2 . \\
\text { Erkkilä \& } \\
\text { Piironen (2020). }\end{array}$ & $\begin{array}{l}\text { 1. A classificação da universidade QS é significativa e positivamente correlacionada } \\
\text { com a infraestrutura de pesquisa (despesas brutas em P\&D, no de pesquisadores, total } \\
\text { de patentes) e desenvolvimento econômico (renda nacional bruta, índice de } \\
\text { competitividade global, índice de inovação global e índice de desenvolvimento } \\
\text { humano); 2. Os rankings locais de inovação objetivam o ensino superior como um } \\
\text { elemento de competitividade global e essa mudança lógica é feita com a ajuda dos } \\
\text { rankings universitários que agora servem para unir a competição global e a inovação } \\
\text { local; os rankings universitários globais existentes são usados nos indicadores } \\
\text { compostos de inovação. }\end{array}$ \\
\hline 3.1 .1 & $\begin{array}{l}\text { Acesso a } \\
\text { TIC }\end{array}$ & $\begin{array}{l}\text { Variáveis: fone } \\
\text { fixo/100 hab.; } \\
\text { celular/100 hab; net } \\
\text { banda larga/ usuário; } \\
\% \text { computador; e \% de } \\
\text { lares c/ internet. }\end{array}$ & $\begin{array}{l}\text { 1. Pereira e Silva } \\
\text { (2010); } 2 \text {. } \\
\text { Jorgensen \& Vu } \\
\text { (2005). }\end{array}$ & $\begin{array}{l}\text { 1. "São imprescindíveis as TICs dentro da dinâmica da inovação no objetivo do } \\
\text { desenvolvimento da economia global ." 2. "... o investimento em equipamentos de TI } \\
\text { e softwares é a fonte mais importante de crescimento e o papel líder do investimento } \\
\text { em TI na aceleração do crescimento das economias do G7 é especialmente } \\
\text { pronunciado nos EUA, onde as TI têm dominado a contribuição do fator capital." }\end{array}$ \\
\hline
\end{tabular}




\begin{tabular}{|c|c|c|c|c|}
\hline 3.1 .2 & $\begin{array}{l}\text { Uso de } \\
\text { TIC }\end{array}$ & $\begin{array}{l}\text { \% dos que usam a } \\
\text { Internet; banda larga } \\
\text { fixa (com fio) de } \\
\text { Internet por } 100 \\
\text { habitantes; (3) } \\
\text { assinaturas de banda } \\
\text { larga móvel ativas } \\
\text { p/100 hab. }\end{array}$ & $\begin{array}{l}\text { 1. Idota, Bunno \& } \\
\text { Tsuji (2013); } 2 . \\
\text { Morais (2014). }\end{array}$ & $\begin{array}{l}\text { 1. "O processo de inovação usando a análise da estrutura de covariância, em } \\
\text { particular com foco no papel das TIC se conclui que (i) a participação da alta direção } \\
\text { e a motivação dos colaboradores no processo de inovação promovem o efeito da } \\
\text { introdução das TIC; (ii) este efeito do uso de TIC aumenta a capacidade de inovação; } \\
\text { em particular, capacidade de conectar ligações externas; (iii) o uso das TIC, a } \\
\text { capacidade de inovação e as ligações externas aumentam a atividade de inovação; e } \\
\text { (iv) o efeito do uso das TIC e a capacidade de inovação promovem a inovação } \\
\text { diretamente."2. "... as práticas pedagógicas com utilização das TIC, em tese, são } \\
\text { consideradas práticas pedagógicas inovadoras." }\end{array}$ \\
\hline 3.1 .3 & $\begin{array}{l}\text { Serviços } \\
\text { gov. on- } \\
\text { line }\end{array}$ & $\begin{array}{l}\mathrm{N}^{\circ} \text { de pontos } \\
\text { marcados por cada } \\
\text { país, normalizado para } \\
\text { um intervalo } 0-1 .\end{array}$ & $\begin{array}{l}\text { 1. Tolbert, } \\
\text { Mossberger \& } \\
\text { McNeal (2008); } 2 \text {. } \\
\text { Lee, Hwang \& } \\
\text { Choi (2012). }\end{array}$ & $\begin{array}{l}\text { 1. "Usando análises de séries temporais e dados de } 50 \text { estados, se descobriu que a } \\
\text { capacidade institucional do estado é importante para a inovação contínua. "2. "... os } \\
\text { EUA, a Austrália e Cingapura desenvolveram políticas de inovação aberta em nível } \\
\text { nacional, facilitando um clima de inovação positivo. Muitos projetos, especialmente } \\
\text { aqueles em plataformas online, foram estabelecidos sob essas políticas. }\end{array}$ \\
\hline 3.1 .4 & $\begin{array}{l}\text { Participaç } \\
\text { ão } \\
\text { eletrônica }\end{array}$ & $\begin{array}{l}\text { Uso online dos } \\
\text { serviços do governo } e \\
\text { de fornecimento de } \\
\text { informações aos } \\
\text { cidadãos ou } \\
\text { compartilhamento de } \\
\text { informações } \\
\text { eletrônicas, interação } \\
\text { com as partes } \\
\text { interessadas e } \\
\text { envolver-se nos } \\
\text { processos de tomada } \\
\text { de decisão. }\end{array}$ & $\begin{array}{l}\text { 1. Li (2011); } 2 . \\
\text { Gomes (2005). }\end{array}$ & $\begin{array}{l}\text { 1. "... entender as maneiras pelas quais os ISS (Intelligent Suport Systems) online } \\
\text { podem ser desenvolvidos com sucesso e descobre que a transparência nas decisões e } \\
\text { a satisfação na tomada de decisões desempenham papéis importantes, } \\
\text { proporcionando um maior senso de empoderamento ao público, incluindo a } \\
\text { percepção de uma relação de poder maior com a agência governamental além de uma } \\
\text { melhor sensação de estar no controle. Essas descobertas são um argumento forte para } \\
\text { o investimento no ISS e fornecem informações úteis para agências governamentais } \\
\text { que desejam desenvolver ou melhorar seus serviços de consultoria online." 2. "A } \\
\text { democracia digital é um expediente semântico empregado para referir-se à } \\
\text { experiência da internet e de dispositivos que lhe são compatíveis, todos eles voltados } \\
\text { para o incremento das potencialidades de participação civil na condução dos } \\
\text { negócios públicos e contribuição para o desenvolvimento econômico-social." }\end{array}$ \\
\hline 3.2.1 & $\begin{array}{l}\text { Prod. } \\
\text { energia } \\
\text { em } \\
\text { GWh/hab }\end{array}$ & $\begin{array}{l}\text { Medições nos } \\
\text { terminais de fonte de } \\
\text { energia: hidrelétrica, } \\
\text { carvão, petróleo, gás, } \\
\text { nuclear, geotérmica, } \\
\text { solar, eólica, ondas } \\
\text { marítimas, e } \\
\text { desperdícios. }\end{array}$ & $\begin{array}{l}\text { 1. Simas e Pacca } \\
\text { (2013); } 2 \text {. } \\
\text { Frankhauser, } \\
\text { Sehlleier \& Stern } \\
\text { (2008). }\end{array}$ & $\begin{array}{l}\text { 1. "A expansão da produção de energia no mundo desenvolvido tem sido mais } \\
\text { concentrada na produção renovável e sustentável. Entre os principais benefícios } \\
\text { socioeconômicos trazidos pelas energias renováveis podem ser citados: a inovação } \\
\text { tecnológica e o desenvolvimento industrial; a geração distribuída e a universalização } \\
\text { do acesso à energia; o desenvolvimento regional e local, especialmente em zonas } \\
\text { rurais; e a criação de empregos." } 2 . \text { "... a inovação tecnológica e a criação de novas } \\
\text { oportunidades para investimento e crescimento econômico são consequências } \\
\text { importantes das políticas climáticas. As mudanças tecnológicas e inovação, no longo } \\
\text { prazo, aumentariam a demanda por trabalho e qualificação. }\end{array}$ \\
\hline 3.2 .2 & $\begin{array}{l}\text { Desempe } \\
\text { nho } \\
\text { logístico }\end{array}$ & $\begin{array}{l}\text { Avaliação } \\
\text { multidimensional do } \\
\text { LPI - Logistics } \\
\text { Performance Index } \\
\text { que classifica } 160 \\
\text { países por dados em } 6 \\
\text { componentes de } \\
\text { medida de } \\
\text { desempenho em } \\
\text { alfandegamento, } \\
\text { qualidade da } \\
\text { infraestrutura e } \\
\text { pontualidade de } \\
\text { remessas. }\end{array}$ & $\begin{array}{l}\text { 1. Ekicia, Kabakb } \\
\text { \& Ülengin (2019); } \\
\text { 2. Oliveira (2002). }\end{array}$ & $\begin{array}{l}\text { 1. O desempenho logístico é fundamental para o comércio nacional e internacional } \\
\text { com efeito direto no desenvolvimento econômico. Devido aos recursos limitados, os } \\
\text { formuladores de políticas precisam de um guia para especificar os fatores que } \\
\text { precisam ser enfocados p/ gerar melhorias imediatas e significativas no desempenho } \\
\text { logístico de seus países. Analisando o efeito dos pilares de competitividade do Índice } \\
\text { de Competitividade Global (GCI) no desempenho logístico (medido pelo LPI), os } \\
\text { resultados indicam que os governos devem focar na prontidão tecnológica, ensino } \\
\text { superior e treinamento, inovação, tamanho do mercado e infraestrutura para facilitar } \\
\text { a melhoria no desempenho logístico de seus países; } 2 \text {. O desempenho logístico é uma } \\
\text { das chaves para uma maior competitividade empresarial, tornando-se a solução para } \\
\text { uma gestão logística mais sustentável, explorando duas tendências que têm vindo a } \\
\text { aproximar os fornecedores de serviços aos clientes. }\end{array}$ \\
\hline 3.2 .3 & $\begin{array}{l}\text { Formação } \\
\text { bruta de } \\
\text { capital }\end{array}$ & $\begin{array}{l}\text { Variação líquida dos } \\
\text { estoques e ativos } \\
\text { (compras de M\&E, } \\
\text { construção de } \\
\text { ferrovias, estradas, } \\
\text { edifícios e habitações. }\end{array}$ & $\begin{array}{l}\text { 1. Arbix (2010); } \\
\text { 2. Nadiri \& } \\
\text { Prucha (1996); } 3 \text {. } \\
\text { Satrovic (2021). }\end{array}$ & $\begin{array}{l}\text { 1. Há novos motores que impulsionam o crescimento das economias além do } \\
\text { investimento, da formação bruta do capital físico e da tecnologia; } 2 \text {. De acordo com } \\
\text { as fontes de produtividade e crescimento endógeno se reconhece o papel central } \\
\text { desempenhado pelos estoques de capital físico e de P\&D; } 3 \text { São reconhecidos os } \\
\text { papéis dos gastos internos brutos em pesquisa e desenvolvimento (P\&D) e da } \\
\text { formação bruta de capital no processo de inovação e sua contribuição para essa } \\
\text { melhoria. }\end{array}$ \\
\hline
\end{tabular}




\begin{tabular}{|c|c|c|c|c|}
\hline .3 .1 & $\begin{array}{l}\text { PIB-unid. } \\
\text { de energia }\end{array}$ & $\begin{array}{l}\text { Medida de uso de } \\
\text { energia, mesurado } \\
\text { pelo PIB (PPC) em } \\
\text { US } \$ / k g \text { de óleo } \\
\text { equivalente de uso de } \\
\text { energia. }\end{array}$ & $\begin{array}{l}\text { 1. Stern \& } \\
\text { Cleveland (2004); } \\
\text { 2. Murad et al. } \\
\text { (2018). }\end{array}$ & $\begin{array}{l}\text { 1. Há uma relação positiva entre o consumo de energia per capita e o } \\
\text { desenvolvimento econômico; } 2 \text {. Na investigação das relações dinâmicas entre } \\
\text { inovação tecnológica, consumo de energia, preço da energia e crescimento } \\
\text { econômico na Dinamarca durante o período de } 1970 \text { a } 2012 \text {, se concluiu que o } \\
\text { consumo de energia e o crescimento econômico são independentes e, portanto, } \\
\text { apoiam uma hipótese neutra para a Dinamarca. }\end{array}$ \\
\hline 3.3 .2 & $\begin{array}{l}\text { Desempe } \\
\text { nho } \\
\text { ambiental }\end{array}$ & $\begin{array}{l}\text { Classificação de } 180 \\
\text { países de } 32 \\
\text { indicadores de } \\
\text { desempenho em } 11 \\
\text { questões categóricas. }\end{array}$ & $\begin{array}{l}\text { 1. Carrion-Flores } \\
\& \text { Innes (2009); } 2 . \\
\text { Theyel (2000). }\end{array}$ & $\begin{array}{l}\text { 1. “... metas de poluição mais rígidas induzem à inovação ambiental; } 2 \text {. As empresas } \\
\text { estão usando práticas como gestão da qualidade total, certificação de fornecedores, } \\
\text { P\&D e o envolvimento dos funcionários em inovação e treinamento para integrar a } \\
\text { gestão ambiental com seus sistemas de produção. Além disso, as empresas com os } \\
\text { mais altos níveis de adoção de práticas ambientais substituíram materiais mais } \\
\text { limpos e mudaram seus processos de produção para uma produção mais limpa. }\end{array}$ \\
\hline 3.3 .3 & $\begin{array}{l}\text { Cert. ISO } \\
14001 / \mathrm{bi} \\
\mathrm{PIB}\end{array}$ & $\begin{array}{l}\text { Especifica os } \\
\text { requisitos p/ gestão } \\
\text { ambiental que uma } \\
\text { org. use p/ melhorar } \\
\text { seu desempenho } \\
\text { ambiental e é } \\
\text { destinado ao uso por } \\
\text { organização que busca } \\
\text { gerenciar suas } \\
\text { responsabilidades } \\
\text { ambientais de forma } \\
\text { sistemática. Aplicável } \\
\text { a qualquer } \\
\text { organização. }\end{array}$ & $\begin{array}{l}\text { 1. Acosta, Padula } \\
\text { \& Wegner. } \\
\text { (2009); 2. Carli, } \\
\text { Oliveira \& Dias } \\
\text { (2013). }\end{array}$ & $\begin{array}{l}\text { 1. As empresas que optam por certificações possuem uma propensão a inovar } \\
\text { equivalente às empresas que não adotaram certificações. Mas a certificação no } \\
\text { aspecto social gera impactos positivos na qualidade de vida dos funcionários; } 2 \text {. O } \\
\text { impacto na qualidade de vida dos trabalhadores é ampliado pelo fato da fazenda } \\
\text { certificada utilizar produtos com menor toxicidade e com os cuidados necessários na } \\
\text { aplicação de agrotóxicos, com o uso correto e consciente de EPI (Equipamento de } \\
\text { Proteção Individual), contribuindo para a manutenção da saúde dos seus } \\
\text { funcionários. Na fazenda certificada há uma preocupação com o bem estar do } \\
\text { funcionário no ambiente de moradia, com os meios de acesso ao transporte, } \\
\text { assistência médica e na disponibilidade de escolas para a educação das crianças, } \\
\text { enquanto nas fazendas não certificadas, todas as mudanças referentes ao bem estar e } \\
\text { qualidade de vida do funcionário só é acatada mediante coação do gestor ou do órgão } \\
\text { fiscalizador dos trabalhadores rurais da região. Não há diferença significativa entre } \\
\text { os salários dos trabalhadores da fazenda certificada e não. }\end{array}$ \\
\hline 4.1 .1 & $\begin{array}{l}\text { Facilid. } \\
\text { obtenção } \\
\text { crédito }\end{array}$ & $\begin{array}{l}\text { Grau em que as leis de } \\
\text { garantias e falências } \\
\text { facilitam os } \\
\text { empréstimos. }\end{array}$ & $\begin{array}{l}\text { 1. Archer, Sharma } \\
\text { e Su (2020); } 2 \text {. } \\
\text { Xiaohua, Yun e } \\
\text { Ran (2015). }\end{array}$ & $\begin{array}{l}\text { 1. "... as empresas com restrição de crédito têm menos probabilidade de serem } \\
\text { inovadoras." 2. "... há uma correlação positiva e significativa entre a intensidade de } \\
\text { R\&D e o fluxo de caixa interno, indicando que a restrição de financiamento } \\
\text { realmente impacta nas atividades de R\&D das empresas industriais. }\end{array}$ \\
\hline 4.1 .2 & $\begin{array}{l}\text { Crédito } \\
\text { int. p. s. } \\
\text { privado }\end{array}$ & $\begin{array}{l}\text { Recursos financeiros } \\
\text { p/ o setor privado: } \\
\text { empréstimos, compras } \\
\text { de títulos não } \\
\text { patrimoniais, créditos } \\
\text { comerciais e outras } \\
\text { contas a receber (com } \\
\text { pedido de reembolso. }\end{array}$ & $\begin{array}{l}\text { 1. Pradhan et al. } \\
(2016) ; 2 \text {. Rapini } \\
(2009) .\end{array}$ & $\begin{array}{l}\text { 1. "... o desenvolvimento do setor financeiro e o aumento da capacidade inovadora } \\
\text { na zona do euro contribuem para o crescimento econômico de longo prazo dos países } \\
\text { da região."; } 2 \text {. "... o sistema financeiro brasileiro moderno, caracterizado pela } \\
\text { presença de consolidadas instituições nacionais e internacionais mas, diferentemente } \\
\text { das experiências de alguns países, os investimentos em inovação e em novas } \\
\text { tecnologias têm sido, prioritariamente, realizados com recursos internos das } \\
\text { empresas. Os recursos externos, na sua maioria, são os fornecidos pelas agências } \\
\text { governamentais de fomento como é o caso da Finep, das FAPs e do BNDES. Há } \\
\text { também recursos de agências como o SEBRAE, que também conta com orçamento } \\
\text { governamental. }\end{array}$ \\
\hline 4.1 .3 & $\begin{array}{l}\text { Microfina } \\
\text { nciamento } \\
\text { bruto }\end{array}$ & $\begin{array}{l}\text { Saldos de } \\
\text { empréstimos brutos } \\
\text { combinados de } \\
\text { instituições de } \\
\text { microfinanças em US\$ } \\
\text { correntes em um país } \\
\text { como \% de seu PIB }\end{array}$ & $\begin{array}{l}\text { 1. Lahimer, Dash } \\
\text { \& Zaiter (2013); } \\
\text { 2. Newman, } \\
\text { Schwarz \& Borgia } \\
\text { (2014). }\end{array}$ & $\begin{array}{l}\text { 1. "... as microfinanças têm um efeito negativo sobre o empreendedorismo de } \\
\text { necessidade. No entanto, seu efeito sobre o empreendedorismo de oportunidade } \\
\text { depende das condições socioeconômicas dos países." 2. "... a oferta de microfinanças } \\
\text { pode se traduzir na criação de novos empreendimentos e no crescimento de } \\
\text { empreendimentos existentes em um contexto de economia emergente, gerando níveis } \\
\text { mais elevados de capital psicológico e social nos clientes." }\end{array}$ \\
\hline 4.2 .1 & $\begin{array}{l}\text { Facilidade } \\
\text { na } \\
\text { proteção } \\
\text { minoritári } \\
\text { os }\end{array}$ & $\begin{array}{l}\text { Soma das pontuações } \\
\text { relativas ao conflito } \\
\text { do índice de regulação } \\
\text { de governança para } \\
\text { com o acionista. }\end{array}$ & $\begin{array}{l}\text { 1. Brown, } \\
\text { Martinsson \& } \\
\text { Petersen (2013); } \\
\text { 2. Belloc (2013). }\end{array}$ & $\begin{array}{l}\text { 1. "... fortes proteções aos acionistas e melhor acesso ao financiamento do mercado } \\
\text { de ações levam a taxas de investimento em P\&D de longo prazo substancialmente } \\
\text { mais altas, especialmente em pequenas empresas, mas não são importantes para o } \\
\text { investimento em capital fixo."; } 2 . \text { "... os defensores da proteção aos acionistas } \\
\text { minoritários afirmam que as instituições jurídicas nacionais que protegem os } \\
\text { pequenos investidores impulsionam os mercados de ações e, por sua vez, o } \\
\text { desempenho de longo prazo dos países." }\end{array}$ \\
\hline
\end{tabular}




\begin{tabular}{|c|c|c|c|c|}
\hline 4.2 .2 & $\begin{array}{l}\text { Capitaliza } \\
\text { ção de } \\
\text { mercado }\end{array}$ & $\begin{array}{l}\text { Preço ações } \mathrm{x} \mathrm{n}^{\circ} \text { de } \\
\text { ações circulando p/ } \\
\text { cias nacionais listadas } \\
\text { sem fundos de invest. } \\
\text { e empresas que } \\
\text { objetivar deter ações } \\
\text { de outras empresas } \\
\text { cotadas. }\end{array}$ & $\begin{array}{l}\text { 1. Dalle Nogare } \\
\text { (2015); 2. Cohen, } \\
\text { Diether \& Malloy } \\
\text { (2013). }\end{array}$ & $\begin{array}{l}\text { 1. "... o desempenho do mercado de capitais não pode servir como indicador } \\
\text { econômico, pois não se constatou evidências de seu desempenho relacionadas ao } \\
\text { desempenho da economia real e da inovação tecnológica."; } 2 \text {. "... a capacidade de } \\
\text { inovação de uma empresa é previsível, persistente e relativamente simples de } \\
\text { calcular, mas o mercado de ações parece ignorar as implicações de sucessos passados } \\
\text { ao avaliar a inovação futura. Mostram que duas empresas que investem o mesmo em } \\
\text { P\&D podem ter caminhos futuros bastante divergentes, mas previsivelmente } \\
\text { divergentes, com base em seus históricos anteriores. }\end{array}$ \\
\hline 4.2 .3 & $\begin{array}{l}\text { Operaçõe } \\
\text { s capital } \\
\text { de risco }\end{array}$ & $\begin{array}{l}\text { Negócios de private } \\
\text { equity com } \\
\text { informações s/ a } \\
\text { localização do } \\
\text { investimento, } \\
\text { investidora, fundos e } \\
\text { crowdfunding e outros } \\
\text { detalhes. }\end{array}$ & $\begin{array}{l}\text { 1. Hirukawa \& } \\
\text { Ueda }(2013) ; 2 . \\
\text { Peneder (2009). }\end{array}$ & $\begin{array}{l}\text { 1. "Os formuladores de políticas normalmente interpretam as relações positivas entre } \\
\text { os investimentos de capital de risco (VC) e as inovações como evidência de que os } \\
\text { investimentos de VC estimulam a inovação."; } 2 \text {. ",", como efeito do financiamento } \\
\text { de capital de risco no desempenho corporativo, se verifica investimentos em } \\
\text { empresas com alto potencial de desempenho e confirmar a função de agregação de } \\
\text { valor em termos de um impacto causal genuíno do capital de risco no crescimento da } \\
\text { empresa, mas não na produção de inovação. }\end{array}$ \\
\hline 4.3.1 & $\begin{array}{l}\text { Tx tarif. } \\
\text { aplic, } \\
\text { média } \\
\text { pond }\end{array}$ & $\begin{array}{l}\text { É a média ponderada } \\
\text { das alíquotas das } \\
\text { importações. }\end{array}$ & $\begin{array}{l}\text { 1. Menezes Filho } \\
\text { et al. (2014); } \\
\text { 2.Radionova \& } \\
\text { Boger (2014). }\end{array}$ & $\begin{array}{l}\text { 1. "... para aumentar a taxa de inovação e o crescimento da produtividade no Brasil o } \\
\text { governo precisa reduzir os tributos aduaneiros e internos."; 2. "... o aumento da carga } \\
\text { fiscal limita as atividades de inovação." }\end{array}$ \\
\hline 4.3.2 & $\begin{array}{l}\text { Intensidad } \\
\text { e } \\
\text { concorrên } \\
\text { cia local }\end{array}$ & $\begin{array}{l}\text { Corresponde à } \\
\text { resposta média à } \\
\text { seguinte pergunta da } \\
\text { pesquisa: "Em seu } \\
\text { país, quão intensa é a } \\
\text { competição nos } \\
\text { mercados locais?" }\end{array}$ & $\begin{array}{l}\text { 1. Boone (2001); } \\
\text { 2. Burlamaqui \& } \\
\text { Proença (2009). }\end{array}$ & $\begin{array}{l}\text { 1. Se os formuladores de políticas decidem aumentar a concorrência em um } \\
\text { determinado setor, devem levar em consideração a possibilidade de que isso aumente } \\
\text { o incentivo para inovar da empresa líder em relação ao incentivo para inovar dos } \\
\text { seguidores; } 2 \text {. A articulação conceitual entre as teorias da concorrência e da } \\
\text { inovação aponta para uma teoria estratégica da firma centrada nas relações } \\
\text { entre concorrência, inovação, competitividade, decisões sob incerteza, } \\
\text { comprometimento e busca de liquidez. }\end{array}$ \\
\hline 4.3.3 & $\begin{array}{l}\text { Escala do } \\
\text { mercado } \\
\text { interno }\end{array}$ & $\begin{array}{l}\text { É mensurado pelo PIB } \\
\text { na PPC em bilhões de } \\
\text { dólares correntes }\end{array}$ & $\begin{array}{l}\text { 1. Symeonidis } \\
(1996) ; 2 \text {. Dias } \\
(2007) .\end{array}$ & $\begin{array}{l}\text { 1. "As ligações entre inovação, estrutura de mercado e tamanho da empresa mostram } \\
\text { que há pouca evidência para apoiar a hipótese Schumpeteriana de que o poder de } \\
\text { mercado e as grandes empresas estimulam inovações."; } 2 \text {. "A metodologia do } \\
\text { Manual de Oslo mede o impacto econômico da inovação através da participação das } \\
\text { vendas totais da empresa. Esse indicador é relativo às inovações de produto. Na } \\
\text { Pintec, esse indicador foi apresentado de forma pouco precisa. As inovações } \\
\text { tecnológicas de produto de quase } 30 \% \text { das empresas inovadoras representam mais de } \\
40 \% \text { de suas vendas no mercado interno. }\end{array}$ \\
\hline 5.1 .1 & $\begin{array}{l}\text { Empregos } \\
\text { intensivos } \\
\text { em } \\
\text { conhecim } \\
\text { ento }\end{array}$ & $\begin{array}{l}\text { Se refere aos } \\
\text { empregos em } \\
\text { ocupações intensivas } \\
\text { em conhecimento } \\
\text { como porcentagem da } \\
\text { força de trabalho. }\end{array}$ & $\begin{array}{l}\text { 1. Miles (2008); } 2 \text {. } \\
\text { Aslesen \& Isaksen } \\
(2007) .\end{array}$ & $\begin{array}{l}\text { 1. "O conhecimento especializado é necessário para lidar com ambientes } \\
\text { organizacionais complexos e poderosas inovações. Serviços e ocupações } \\
\text { especializadas, com aplicação de alto nível de conhecimento técnico e profissional, } \\
\text { também refletem a contínua intensificação da divisão do trabalho. A proliferação de } \\
\text { especialistas exige necessariamente novas capacidades de coordenação, integração e } \\
\text { síntese desse conhecimento. Esses processos são extremamente importantes para o } \\
\text { desenvolvimento econômico e a inovação"; } 2 \text {. "... consideram que os serviços } \\
\text { intensivos em conhecimento têm uma importância cada vez maior para as atividades } \\
\text { de inovação em uma economia mais baseada no conhecimento. }\end{array}$ \\
\hline 5.1 .2 & $\begin{array}{l}\text { Empresas } \\
\text { fornecem } \\
\text { treinamen } \\
\text { to formal }\end{array}$ & $\begin{array}{l}\text { Se refere a \% de } \\
\text { empresas que } \\
\text { oferecem programas } \\
\text { de treinamento formal } \\
\text { para seus funcionários } \\
\text { permanentes em } \\
\text { tempo integral. }\end{array}$ & $\begin{array}{l}\text { 1. Dostie (2017); } \\
\text { 2. Tolbert \& } \\
\text { McNeal (2008). }\end{array}$ & $\begin{array}{l}\text { 1. "... parte da máxima que indica que o estoque de capital humano da empresa é um } \\
\text { determinante importante da sua capacidade de inovar e testa a hipótese de que } \\
\text { qualquer aumento neste estoque por meio de treinamento patrocinado pela empresa } \\
\text { pode levar a mais inovação."; } 2 \text {. "... o investimento em treinamento para inovação } \\
\text { tem o potencial de ajudar as empresas a criarem ofertas de produtos mais bem- } \\
\text { sucedidos e que os esforços para otimizar processos formais e integrar métodos ágeis } \\
\text { ao desenvolvimento levem à sistemas de inovação mais eficientes". }\end{array}$ \\
\hline 5.1 .3 & $\begin{array}{l}\text { GERD } \\
\text { realizado } \\
\text { empresas }\end{array}$ & $\begin{array}{l}\text { Se refere a despesa } \\
\text { bruta em } \mathrm{P} \& \mathrm{D} \\
\text { realizada pelas } \\
\text { empresas como } \\
\text { percentagem do PIB }\end{array}$ & $\begin{array}{l}\text { 1.Katz (2006); } 2 \text {. } \\
\text { Olvido \& Sanchez } \\
(2017)\end{array}$ & $\begin{array}{l}\text { 1. "Indicadores de desempenho como riqueza nacional (PIB per capita), intensidade } \\
\text { de P\&D (GERD/PIB) e impacto científico (citações/artigos) são usados para } \\
\text { comparar os sistemas de inovação; } 2 . \text { "... agricultura, ciências humanas e sociais são } \\
\text { geralmente financiadas pelo governo enquanto engenharia/tecnologia, medicina e } \\
\text { ciências da saúde são impulsionadas p/ empresas, e as ciências naturais, p/ ambas. }\end{array}$ \\
\hline
\end{tabular}




\begin{tabular}{|c|c|c|c|c|}
\hline 5.1 .4 & $\begin{array}{l}\text { GERD } \\
\text { financ. } \\
\text { empresas }\end{array}$ & $\begin{array}{l}\text { Se refere aos gastos } \\
\text { brutos em P\&D } \\
\text { financiados por } \\
\text { empresas como } \\
\text { porcentagem do total } \\
\text { das despesas brutas. }\end{array}$ & $\begin{array}{l}\text { 1. Samoilikova } \\
\text { (2020); 2. Gao \& } \\
\text { Guan (2009). }\end{array}$ & $\begin{array}{l}\text { 1. Confirma empiricamente e teoricamente que a porcentagem da GERD no PIB, a } \\
\text { parcela da GERD representada pelo setor empresarial e a GERD financiado por } \\
\text { empresas, o volume de crédito interno ao setor privado e facilidade de regulação / } \\
\text { resolução de insolvência - esses indicadores têm uma forte dependência direta } \\
\text { (positiva) e significância de correlação com o nível geral de desenvolvimento } \\
\text { inovador. 2. Com a relação à GERD e produto interno bruto (PIB) espera-se que, } \\
\text { com o aumento do PIB e da intensidade de P\&D, a China apresente um aumento } \\
\text { sustentado dos indicadores relacionados à ciência e tecnologia. }\end{array}$ \\
\hline 5.1 .5 & $\begin{array}{l}\text { Mulheres } \\
\text { pós } \\
\text { graduadas } \\
\text { empregad } \\
\text { as }\end{array}$ & $\begin{array}{l}\% \text { de mulheres } \\
\text { empregadas com } \\
\text { profissionais de grau } \\
\text { avançado fora do total } \\
\text { de empregados que } \\
\text { estavam em uma das } \\
\text { seguintes categorias: } \\
\text { (1) emprego } \\
\text { remunerado; ou (2) } \\
\text { trabalho autônomo. }\end{array}$ & $\begin{array}{l}\text { 1. Chau \& Quire } \\
\text { (2018); } 2 \text {. Reuvers } \\
\text { et al. }(2008)\end{array}$ & $\begin{array}{l}\text { 1. Há uma maior inclusão das mulheres em novas dimensões não reconhecidas } \\
\text { anteriormente no setor de tecnologia predominantemente dominado por homens. } \\
\text { Embora a pesquisa feminista existente possa olhar para as desvantagens gerais que as } \\
\text { mulheres têm no local de trabalho, poucas examinaram a gênese e a constituição da } \\
\text { feminilidade para entender quais novas contribuições podem ser trazidas para a } \\
\text { gestão da inovação e como essas diferentes visões podem mudar a conduta da } \\
\text { previsão corporativa no setor de tecnologia. } 2 . \text { "... há uma relação positiva e } \\
\text { significativa entre liderança transformacional e comportamento de trabalho inovador. } \\
\text { Além disso, o gênero do gerente modera esta última relação, indicando que os } \\
\text { funcionários relatam um comportamento mais inovador quando a liderança } \\
\text { transformacional é exibida por homens em comparação com mulheres, confirmando } \\
\text { a hipótese de preconceito de gênero." }\end{array}$ \\
\hline 5.2 .1 & $\begin{array}{l}\text { Colaboraç } \\
\text { ão pesq - } \\
\text { univ -emp }\end{array}$ & $\begin{array}{l}\text { Resposta média à } \\
\text { pergunta: “Em seu } \\
\text { país, até que ponto as } \\
\text { empresas e } \\
\text { universidades } \\
\text { colaboram c/ P\&D? }\end{array}$ & $\begin{array}{l}\text { 1. Abramo, } \\
\text { D’Angelo \& } \\
\text { Costa (2011); } 2 . \\
\text { Lee (2000). }\end{array}$ & $\begin{array}{l}\text { 1. Acadêmicos e formuladores de políticas reconhecem que a colaboração entre a } \\
\text { indústria e as instituições públicas de pesquisa é uma necessidade para a inovação e } \\
\text { o desenvolvimento econômico nacional; } 2 \text {. O conceito de colaboração universidade- } \\
\text { empresa é um experimento social importante no sistema de inovação do país. A } \\
\text { sustentabilidade dessa experiência colaborativa é garantida pelo fato dos } \\
\text { participantes da colaboração em pesquisa parecer receber benefícios significativos, } \\
\text { esperados ou não. }\end{array}$ \\
\hline 5.2 .2 & $\begin{array}{l}\text { Estado } \\
\text { financiam } \\
\text {. clusters }\end{array}$ & $\begin{array}{l}\text { Resposta média à } \\
\text { pergunta: "Em seu } \\
\text { país, quão difundidos } \\
\text { são clusters bem } \\
\text { desenvolvidos e } \\
\text { profundos?" }\end{array}$ & $\begin{array}{l}\text { 1. Stepanova } \\
\text { (2009); 2. Colgan } \\
\& \text { Baker (2003). }\end{array}$ & $\begin{array}{l}\text { 1. Os fatores chave para a competitividade e o desenvolvimento sustentável de todas } \\
\text { as economias nos dias de hoje são ciência, desenvolvimento tecnológico, inovação, } \\
\text { pesquisa competitiva para inovação, colaboração universidade-indústria em P\&D, } \\
\text { qualidade das instituiçães de pesquisa científica e o estado do desenvolvimento de } \\
\text { clusters. 2. Os clusters, especialmente aqueles baseados de alguma forma na } \\
\text { inovação tecnológica, tornaram-se um conceito-chave no desenvolvimento regional. } \\
\text { Mas a medição e avaliação precisas do conceito são difíceis. }\end{array}$ \\
\hline 5.2 .3 & $\begin{array}{l}\text { GERD } \\
\text { financiad } \\
\text { o do } \\
\text { exterior }\end{array}$ & $\begin{array}{l}\text { Calculada como a } \\
\text { porcentagem da } \\
\text { despesa bruta em } \\
\text { P\&D financiada do } \\
\text { exterior em bilhões } \\
\text { em moeda nacional } \\
\text { em relação ao PIB. }\end{array}$ & $\begin{array}{l}\text { 1. Bastos (2016); } \\
\text { 2. Omar (2019). }\end{array}$ & $\begin{array}{l}\text { 1.O agregado principal usado para comparações internacionais pela OECD é a } \\
\text { GERD, consistindo na despesa total (atual e imobilizada) em P\&D por todas as } \\
\text { empresas, institutos de pesquisa, laboratórios de universidades e do governo, etc., } \\
\text { excluindo-se as despesas do P\&D financiadas por empresas domésticas, mas } \\
\text { realizadas pelo exterior. } 2 \text {. Estuda a associação entre inovação - medida pelo GERD - } \\
\text { e desempenho econômico - representado pelo PIB. }\end{array}$ \\
\hline 5.2 .4 & $\begin{array}{l}\text { JV ou } \\
\text { aliança } \\
\text { estrat/bi } \\
\text { PIB }\end{array}$ & $\begin{array}{l}\text { Negócios conjuntos, } \\
\text { acordos de aliança } \\
\text { estratégica e joint } \\
\text { ventures, em } \mathrm{n}^{\circ} \text { de } \\
\text { negócios, com } \\
\text { contagem fracionária. }\end{array}$ & $\begin{array}{l}\text { 1. Zajac, Golden } \\
\text { \& Shortel (1991); } \\
\text { 2. Ma et al. } \\
\text { (2015). }\end{array}$ & $\begin{array}{l}\text { 1. As organizações têm se voltado cada vez mais para formas organizacionais } \\
\text { alternativas como joint ventures e empreendimentos corporativos internos para } \\
\text { aprimorar a inovação. } 2 \text {. Com os dados de mais de } 400 \text { joint ventures internacionais } \\
\text { no setor manufatureiro, mostram que, embora o investimento total em P\&D possa } \\
\text { aumentar as vendas globais de produtos das joint ventures internacionais da China } \\
\text { trazidas por inovações de novos produtos, serviços profissionais locais e } \\
\text { infraestrutura, incluindo universidades locais e institutos de pesquisa, podem facilitar } \\
\text { a inovação de produtos e pedidos de patentes. }\end{array}$ \\
\hline 5.2 .5 & $\begin{array}{l}\text { Família } \\
\text { patentes } \\
\text { 2+órgãos }\end{array}$ & $\begin{array}{l}\text { Famílias/conjunto de } \\
\text { pedidos de patentes } \\
\text { inter-relacionados } \\
\text { arquivado em } \\
\text { países/jurisdições para } \\
\text { proteger a mesma } \\
\text { invenção. }\end{array}$ & $\begin{array}{l}\text { 1. National } \\
\text { Research Council } \\
\text {, } 2004 \text { apud } \\
\text { Sampat (2018); } 2 . \\
\text { Sternitzke (2009). }\end{array}$ & $\begin{array}{l}\text { 1. Os efeitos das patentes sobre os incentivos à inovação são mais fortes em alguns } \\
\text { setores. Os efeitos da política de patentes sobre a inovação são provavelmente } \\
\text { específicos do setor, assim como os custos e benefícios do fortalecimento ou } \\
\text { enfraquecimento da proteção à patente. } 2 \text {. Um indicador frequentemente usado para } \\
\text { avaliar os pontos fortes tecnológicos das nações são as patentes registradas na } \\
\text { América do Norte, Europa e Ásia. O número de famílias de patentes por país é } \\
\text { função da especialização tecnológica e das estratégias de patenteamento nacionais. }\end{array}$ \\
\hline
\end{tabular}




\begin{tabular}{|c|c|c|c|c|}
\hline 5.3 .1 & $\begin{array}{l}\text { Valores } \\
\text { pagos uso } \\
\text { de PI }\end{array}$ & $\begin{array}{l}\text { Cobranças } \mathrm{p} / \text { uso de } \\
\text { PI não incluídos } \\
\text { outros pagamentos c/ } \\
\% \text { do comércio (média } \\
\text { dos } 3 \text { anos mais } \\
\text { recentes). }\end{array}$ & $\begin{array}{l}\text { 1. Acemoglu e } \\
\text { Akcigit (2006); } 2 \text {. } \\
\text { Henry \& Stiglitz } \\
(2010)\end{array}$ & $\begin{array}{l}\text { 1. A política de DPI regula se os seguidores de uma indústria podem copiar a } \\
\text { tecnologia do líder. Com a proteção total de patentes, os seguidores podem alcançar } \\
\text { o líder em sua indústria, fazendo eles próprios a(s) mesma(s) inovação(ões) ou } \\
\text { fazendo alguns pagamentos pré-especificados aos líderes tecnológicos. } 2 \text {. O sistema } \\
\text { de patenteamento atual pode impedir tanto a inovação quanto a disseminação. }\end{array}$ \\
\hline 5.3 .2 & $\begin{array}{l}\text { Importaçõ } \\
\text { es } \\
\text { líquidas - } \\
\text { alta } \\
\text { tecnologia }\end{array}$ & $\begin{array}{l}\text { Produtos com alta } \\
\text { intensidade de P\&D, } \\
\text { definidos pela } \\
\text { Classificação do } \\
\text { Eurostat }\end{array}$ & $\begin{array}{l}\text { 1. Ismail (2013); } \\
\text { 2. Chen, Zhang \& } \\
\text { Zheng (2017) }\end{array}$ & $\begin{array}{l}\text { 1. As atividades de inovação são os principais motores da exportação de produtos de } \\
\text { alta tecnologia nos países asiáticos. Os países importadores, à medida que a inovação } \\
\text { iniciada pelo IED por meio do processo de aprendizado por importação está se } \\
\text { tornando mais forte, a importação de produtos de alta tecnologia diminui; } 2 \text {. As } \\
\text { importações de bens intermediários tendem a aumentar a intensidade de P\&D das } \\
\text { empresas importadoras e as exportações aumentam a intensidade de P\&D das } \\
\text { importadoras. }\end{array}$ \\
\hline 5.3 .3 & $\begin{array}{l}\text { Importaçã } \\
\text { o serviços } \\
\text { TIC }\end{array}$ & $\begin{array}{l}\text { Se refere aos serviços } \\
\text { de telecomunicações, } \\
\text { informática e } \\
\text { informação como uma } \\
\text { porcentagem do } \\
\text { comércio total de } \\
\text { acordo com a OCDE. }\end{array}$ & $\begin{array}{l}\text { 1. Biryukova e } \\
\text { Matiukhina } \\
(2019) 12 \text {. Van } \\
\text { Ark \& Piatkowski } \\
\text { (2004). }\end{array}$ & $\begin{array}{l}\text { 1. A análise da participação dos BRICS no comércio internacional de serviços de } \\
\text { TIC indicam que a vantagem comparativa revelada permite determinar a dinâmica da } \\
\text { vantagem comparativa para o comércio de serviços de TIC no BRICS e que, apesar } \\
\text { do aumento no volume das operações de exportação no comércio de serviços de TIC, } \\
\text { seu nível de competitividade está em declínio. 2. As indústrias manufatureiras que } \\
\text { investiram pesadamente em TIC foram fundamentais para o processo de } \\
\text { reestruturação. Como tal, as TIC podem ter sido uma fonte importante de } \\
\text { crescimento, mas provavelmente uma fonte temporária de convergência. }\end{array}$ \\
\hline 5.3 .4 & $\begin{array}{l}\text { Fluxos líq } \\
\text { entrada de } \\
\text { IED }\end{array}$ & $\begin{array}{l}\text { Mostra o fluxo líquido } \\
\text { de entradas na } \\
\text { economia relatora dos } \\
\text { investidores } \\
\text { estrangeiros dividido } \\
\text { pelo PIB. }\end{array}$ & $\begin{array}{l}\text { 1. Dhrifi, (2015); } \\
\text { 2. Girma, Gong } \\
\text { \& Görg (2008). }\end{array}$ & $\begin{array}{l}\text { 1. Há um efeito positivo e significativo do IED sobre o crescimento econômico } \\
\text { apenas para países de renda média e alta, enquanto para países de baixa renda não } \\
\text { têm um impacto positivo sobre essas economias; } 2 \text {. A entrada de IED no nível } \\
\text { setorial está positivamente associada à atividade inovadora nacional apenas entre as } \\
\text { empresas que realizam sua própria pesquisa e desenvolvimento ou que têm bom } \\
\text { acesso ao financiamento interno. }\end{array}$ \\
\hline 5.3 .5 & $\begin{array}{l}\text { Talentos } \\
\text { área de } \\
\text { pesq. }\end{array}$ & $\begin{array}{l}\text { Equivalência de tempo } \\
\text { integral de } \\
\text { pesquisadores } \\
\text { engajados na } \\
\text { Inovação. }\end{array}$ & $\begin{array}{l}\text { 1. Wang, Jiang } \\
\& \text { Li (2010); } 2 \text {. } \\
\text { Wang, Rodan, } \\
\text { Fruin \& Xu } \\
\text { (2013). }\end{array}$ & $\begin{array}{l}\text { 1. A formação de equipes de talentos de inovação em tecnologia está diretamente } \\
\text { relacionada à sobrevivência e ao desenvolvimento das empresas; } 2 \text {. O conhecimento } \\
\text { e as redes sociais influenciam onde os pesquisadores buscam por descobertas. }\end{array}$ \\
\hline 6.1 .1 & $\begin{array}{l}\text { Patentes } \\
\text { por } \\
\text { origem }\end{array}$ & $\begin{array}{l}\mathrm{N}^{\circ} \text { de pedidos de } \\
\text { patentes de residentes } \\
\text { depositados em det. } \\
\text { escritório. }\end{array}$ & $\begin{array}{l}\text { 1. Nagaoka, } \\
\text { Motohashi \& } \\
\text { Goto (2010); } 2 \text {. } \\
\text { Pavitt (1985). }\end{array}$ & $\begin{array}{l}\text { 1. As patentes são um indicador de inovação; } 2 \text {. Os avanços na tecnologia da } \\
\text { informação aumentaram o uso real e potencial das patentes como medidas substitutas } \\
\text { de atividades inovadoras. }\end{array}$ \\
\hline 6.1 .2 & $\begin{array}{l}\text { Pedidos } \\
\text { de } \\
\text { patentes } \\
\text { PCT } \\
\text { p/origem }\end{array}$ & $\begin{array}{l}\mathrm{N}^{\circ} \text { de pedidos de } \\
\text { Tratado de } \\
\text { Cooperação de } \\
\text { Patentes (PCT). }\end{array}$ & $\begin{array}{l}\text { 1. O’Neale \& } \\
\text { Hendy (2012); } 2 . \\
\text { Wachowska } \\
\text { (2018); 3. Boing } \\
\text { \& Muller (2016). }\end{array}$ & $\begin{array}{l}\text { 1. O número total de patentes produzidas por um país é frequentemente usado como } \\
\text { um indicador de inovação; } 2 \text {. Pesquisa quais perdas na forma de capacidade reduzida } \\
\text { de gerar inovações - medidas } \mathrm{p} / \mathrm{n}^{\circ} \text { de invenções PCT e pelos autores dessas } \\
\text { invenções; 3. Propõem um novo índice de qualidade baseado em citações de } \\
\text { relatórios de pesquisa internacionais e } \mathrm{n}^{\text {os }} \text { ajustados de qualidade comparáveis } \\
\text { internacionalmente para pedidos feitos sob o PCT. }\end{array}$ \\
\hline 6.1 .3 & $\begin{array}{l}\text { Modelos } \\
\text { utili/ } \\
\text { origem }\end{array}$ & $\begin{array}{l}\mathrm{N}^{\circ} \text { de pedidos de } \mathrm{MU} \\
\text { de residentes } \\
\text { depositados no } \\
\text { escritório nacional de } \\
\text { patentes }\end{array}$ & $\begin{array}{l}\text { 1. Suthersanen } \\
(2019) ; 2 \text {. Beneito } \\
(2006) \text {. }\end{array}$ & $\begin{array}{l}\text { 1. Os direitos de propriedade intelectual (PI) impactam a inovação de diversas } \\
\text { maneiras; } 2 \text {. Considera patentes e modelos de utilidade como medidas de produção } \\
\text { de inovação. Patentes e modelos de utilidade são considerados aproximados para } \\
\text { inovações significativas e incrementais. }\end{array}$ \\
\hline 6.1 .4 & $\begin{array}{l}\text { Artigos } \\
\text { técnicos e } \\
\text { científicos } \\
\text {. }\end{array}$ & $\begin{array}{l}\text { Se técnicas se refere } \\
\text { ao número de artigos } \\
\text { de periódicos } \\
\text { científicos e técnicos }\end{array}$ & $\begin{array}{l}\text { 1. Gibson \& } \\
\text { Klocker (2004); } 2 . \\
\text { Van Rooij (2014). }\end{array}$ & $\begin{array}{l}\text { 1. A criatividade e as 'indústrias criativas' são componentes cada vez mais comuns do } \\
\text { discurso do desenvolvimento econômico urbano, especialmente após o lançamento } \\
\text { de um conjunto de livros importantes que se tornaram populares entre planejadores } \\
\text { de desenvolvimento econômico e formuladores de políticas culturais; } 2 \text {. As } \\
\text { universidades são cada vez mais vistas como motores de inovação, fornecendo mão } \\
\text { de obra treinada e publicações para a sociedade. }\end{array}$ \\
\hline 1.5 & Índice $\mathrm{H}$ & $\begin{array}{l}\text { Índice } \mathrm{H} \text { é o } \mathrm{n}^{\circ} \mathrm{de} \\
\text { artigos publicados da } \\
\text { economia c/ no } \\
\text { mínimo H citações. }\end{array}$ & $\begin{array}{l}\text { 1. Dhamdher } \\
\text { (2018); } 2 \text {. Lima, } \\
\text { Velho \& Farias } \\
\text { (2012). }\end{array}$ & $\begin{array}{l}\text { 1.. O critério mais importante na graduação ou classificação de instituições de ensino } \\
\text { superior, como faculdades ou universidades é o critério de pesquisa; } 2 \text {. O índice H é } \\
\text { uma ferramenta para mensurar a quantidade da atividade de produção científica e } \\
\text { com isso conhecer o impacto desses autores pesquisadores, baseando-se nas }\end{array}$ \\
\hline
\end{tabular}


Research, Society and Development, v. 11, n. 3, e19911326092, 2022

(CC BY 4.0) | ISSN 2525-3409 | DOI: http://dx.doi.org/10.33448/rsd-v11i3.26092

\begin{tabular}{|c|c|c|c|c|}
\hline & & & & publicações que foram citados. \\
\hline 6.2 .1 & $\begin{array}{l}\text { Taxa PIB- } \\
\text { trabalhad } \\
\text { or }\end{array}$ & $\begin{array}{l}\text { É a média dos } 3 \\
\text { últimos anos } \\
\text { disponíveis referente } \\
\text { ao crescimento PIB } \\
\text { por pessoa envolvida. }\end{array}$ & $\begin{array}{l}\text { 1. Kurt \& Kurt } \\
(2015) ; 2 . \\
\text { Preenen, Vergeer } \\
\text { \& Kraan (2015); } \\
\text { 3. Vieira, Neira \& } \\
\text { Vázquez (2011). }\end{array}$ & $\begin{array}{l}\text { 1. Há uma relação positiva entre inovação e produtividade do trabalho; } 2 \text {. As práticas } \\
\text { internas de flexibilidade do trabalho beneficiam tanto a produtividade do trabalho } \\
\text { quanto o desempenho inovador; } 3 \text {. Entre alguns dos fatores que determinam a } \\
\text { existência de bons níveis de produtividade do trabalho, destaca-se a relação entre } \\
\text { inovação e produtividade co-objetivando enfatizar a importância do progresso } \\
\text { tecnológico no desenvolvimento. }\end{array}$ \\
\hline 6.2 .2 & $\begin{array}{l}\text { Novas } \\
\text { empresas/ } \\
\text { mi hab. }\end{array}$ & $\begin{array}{l}\text { Corresponde aos } \\
\text { novos registros de } \\
\text { empresas por } 1.000 \\
\text { habitantes em idade } \\
\text { produtiva (15-64 } \\
\text { anos). }\end{array}$ & $\begin{array}{l}\text { 1. Etzkowitz, } \\
\text { Webster \& } \\
\text { Healey, } 1998 \\
\text { apud Powers \& } \\
\text { McDougall } \\
\text { (2005); } \text {. Oliveira } \\
\text { \& Fillion (2008). }\end{array}$ & $\begin{array}{l}\text { 1. A criação de empresas de base tecnológica com possibilidade de atuação em nível } \\
\text { nacional e internacional cria riquezas, gera empregos, diversifica o parque industrial, } \\
\text { contribui para o desenvolvimento do país, para a progressão científica e para a } \\
\text { melhoria das condiçães de vida da população; } 2 \text {. A criação de empresas estimula o } \\
\text { empreendedorismo tecnológico e a inovação, com benefícios para a organização que } \\
\text { deu origem à empresa, para o pesquisador-empreendedor, e para a sociedade. }\end{array}$ \\
\hline 6.2 .3 & $\begin{array}{l}\text { Gastos } \\
\text { com } \\
\text { software }\end{array}$ & $\begin{array}{l}\text { Valor do software } \\
\text { empacotado, } \\
\text { comprado/alugado, } \\
\text { sistemas de banco de } \\
\text { dados, operacionais, } \\
\text { ferramentas de } \\
\text { programação, } \\
\text { utilitários e } \\
\text { aplicativos. }\end{array}$ & $\begin{array}{l}\text { 1. Evans, Hagiu \& } \\
\text { Schmalensee, } \\
\text { 2008, apud } \\
\text { Jacobides, } \\
\text { Cenmamo \& } \\
\text { Gawe (2018); 2. } \\
\text { Figueiredo (2006). }\end{array}$ & $\begin{array}{l}\text { 1. Plataformas de software são os motores invisíveis que criaram ou transformaram } \\
\text { quase todas as grandes indústrias no último quarto de século; } 2 \text {. A capacidade de } \\
\text { inovação tecnológica institui um conjunto de recursos relativos a ativos tangíveis } \\
\text { (sistemas técnicos-físicos, base de dados, softwares) e intangíveis (técnicas de gestão } \\
\text { e produção, rotinas organizacionais implícitas e explícitas, estruturas } \\
\text { organizacionais, valores e normas) pertencentes à organização. }\end{array}$ \\
\hline 6.2 .4 & $\begin{array}{l}\text { Certif. } \\
\text { Quali. } \\
\text { ISO } 9001\end{array}$ & $\begin{array}{l}\text { Requisitos p/ a } \\
\text { qualidade do sistema } \\
\text { de gestão quando uma } \\
\text { cia precisa demonstrar } \\
\text { sua capacidade de } \\
\text { fornecer produtos e } \\
\text { serviços que atendam } \\
\text { ao cliente. }\end{array}$ & $\begin{array}{l}\text { 1. Manders, Vries } \\
\text { \& Blind (2016); } 2 . \\
\text { Terziovski \& } \\
\text { Guerrero (2014). }\end{array}$ & $\begin{array}{l}\text { 1. Não está claro se a ISO } 9001 \text { incentiva ou atrapalha a inovação de produtos, } \\
\text { porque até o momento houve pouca discussão científica; } 2 \text {. A certificação ISO } 9000 \\
\text { não tem uma relação estatisticamente significativa com as medidas de desempenho } \\
\text { de inovação de produto, como o "tempo de chegada ao mercado" de novos produtos. }\end{array}$ \\
\hline 6.2 .5 & $\begin{array}{l}\text { Prod.- alta } \\
\text { e alta- } \\
\text { média } \\
\text { tecnologia }\end{array}$ & $\begin{array}{l}\text { Produção de alta e } \\
\text { média-alta tecnologia } \\
\text { como uma } \\
\text { porcentagem da } \\
\text { produção total de } \\
\text { manufaturas, com } \\
\text { base na OCDE. }\end{array}$ & $\begin{array}{l}\text { 1. Sandven, Smith } \\
\text { \& Kaloudis } \\
\text { (2005); } 2 \text {. Cozza } \\
\text { (2012). }\end{array}$ & $\begin{array}{l}\text { 1. As indústrias de alta tecnologia impulsionam os processos de crescimento e que } \\
\text { são as fontes de crescimento da produção, do emprego e da produtividade na } \\
\text { economia do conhecimento; } 2 \text {. O impacto da inovação de produto no desempenho } \\
\text { econômico de empresas que operam em indústrias de média e alta tecnologia indica } \\
\text { de forma positiva e significativa aumento de sua lucratividade e crescimento. }\end{array}$ \\
\hline 6.3 .1 & $\begin{array}{l}\text { Valores } \\
\text { rec. uso } \\
\text { de TI }\end{array}$ & $\begin{array}{l}\text { Cobranças pelo uso de } \\
\text { propriedade } \\
\text { intelectual não } \\
\text { incluídas outras } \\
\text { receitas, em termos de } \\
\text { média de } 3 \text { anos mais } \\
\text { recentes ou dados } \\
\text { disponíveis. }\end{array}$ & $\begin{array}{l}\text { 1. Chiarini \& } \\
\text { Gonçalves Silva } \\
\text { (2016); } 2 \text {. } \\
\text { Gregory (2008). }\end{array}$ & $\begin{array}{l}\text { 1. Parece evidente que a maioria dos novos conhecimentos tecnológicos é produzida } \\
\text { em sistemas de inovação maduros e se ressalta que esses países pagam mais do que } \\
\text { os mais atrasados pelo uso da propriedade intelectual, mas também são mais bem } \\
\text { remunerados do que seus congêneres menos avançados; } 2 \text {. Um regime de DPI bem } \\
\text { equilibrado é importante para o desenvolvimento, pois incentiva tanto o IDE como o } \\
\text { doméstico para o benefício geral de um país. }\end{array}$ \\
\hline 6.3 .2 & $\begin{array}{l}\text { Exp. } \\
\text { líqui. - } \\
\text { alta } \\
\text { tecnologia } \\
\text { l. }\end{array}$ & $\begin{array}{l}\text { Exp. de produtos de } \\
\text { alta tecnologia menos } \\
\text { as reexportações c/ } \\
\text { porcentagem do } \\
\text { comércio. }\end{array}$ & $\begin{array}{l}\text { 1. Sandu \& } \\
\text { Ciocanel (2014); } \\
\text { 2. Falk (2009). }\end{array}$ & $\begin{array}{l}\text { 1. Há uma relação causal entre as variáveis de inovação e o nível das exportações de } \\
\text { alta tecnologia da EU; } 2 \text {. fornece novas evidências sobre o impacto da mudança na } \\
\text { participação das exportações de alta tecnologia no crescimento econômico nos países } \\
\text { da OCDE. }\end{array}$ \\
\hline 6.3 .3 & $\begin{array}{l}\text { Exp. de } \\
\text { serviços - } \\
\text { TIC }\end{array}$ & $\begin{array}{l}\text { Correspondente aos } \\
\text { serviços de } \\
\text { telecomunicações, } \\
\text { informática e } \\
\text { informação. }\end{array}$ & $\begin{array}{l}\text { 1. Pesole (2015); } \\
\text { 2. Hanna (2010). }\end{array}$ & $\begin{array}{l}\text { 1. O papel das TIC como um impulsionador e facilitador da inovação foi } \\
\text { amplamente reconhecido; } 2 \text {. A TIC é um facilitador p/ a entrega de serviços públicos } \\
\text { e comerciais e uma competência tecnológica central } \mathrm{p} / \text { transformar a economia, } \\
\text { sector-chave da economia do conhecimento. A aplicação dessa competência } \\
\text { transforma negócios e promove a inovação }\end{array}$ \\
\hline
\end{tabular}




\begin{tabular}{|c|c|c|c|c|}
\hline 6.3 .4 & $\begin{array}{l}\text { Fluxos } \\
\text { líquido de } \\
\text { saída do } \\
\text { IED }\end{array}$ & $\begin{array}{l}\text { Média dos três anos } \\
\text { mais recentes dos } \\
\text { fluxos de capital de } \\
\text { investimento direto } \\
\text { em uma economia. }\end{array}$ & $\begin{array}{l}\text { 1. Jungmittag \& } \\
\text { Welfens (2017); } \\
\text { 2. Borensztei, De } \\
\text { Gregorio \& Lee } \\
\text { (1998). }\end{array}$ & $\begin{array}{l}\text { 1. O debate econômico internacional sobre os benefícios para o desenvolvimento } \\
\text { relacionados aos IED e induzidos pela inovação são amplamente negligenciados, } \\
\text { mesmo pela UE e os EUA, principais países anfitriões e fonte de IDE; } 2 \text {. O IDE é um } \\
\text { veículo importante para a transferência de tecnologia, contribuindo relativamente } \\
\text { mais para o crescimento do que o investimento doméstico. }\end{array}$ \\
\hline 7.1.1 & $\begin{array}{l}\text { Marcas } \\
\text { registrada } \\
\text { s por } \\
\text { origem }\end{array}$ & $\begin{array}{l}\text { Consiste em palavras } \\
\text { e/ou combinações } \\
\text { (slogans, nomes, sons, } \\
\text { logotipos, figuras, } \\
\text { letras, } \mathrm{n}^{\circ} \text { e imagens.) }\end{array}$ & $\begin{array}{l}\text { 1. Malmberg } \\
(2005) ; 2 . \\
\text { Mendonça, } \\
\text { Pereira e Godinho } \\
\text { (2004). }\end{array}$ & $\begin{array}{l}\text { 1. Se pode explorar a possibilidade de usar estatísticas de marcas como um indicador } \\
\text { de inovação nova para a empresa; } 2 \text {. Propõem as marcas como um indicador } \\
\text { complementar no portfólio de ferramentas empíricas de estudos de inovação e } \\
\text { dinâmica industrial disponíveis. }\end{array}$ \\
\hline 7.1 .2 & $\begin{array}{l}\text { Valores } \\
\text { de marcas } \\
\text { globais }\end{array}$ & $\begin{array}{l}\text { Corresponde a soma } \\
\text { dos valores globais } \\
\text { das marcas dentro das } \\
\text { principais } 5.000 \mathrm{c} / \\
\text { porcentagem do PIB. }\end{array}$ & $\begin{array}{l}\text { 1. Yoon e Tello } \\
\text { (2009); } 2 . \\
\text { Moliner- } \\
\text { Velázquez, } \\
\text { Fuentes-Blasco \& } \\
\text { Gil-Saura (2019). }\end{array}$ & $\begin{array}{l}\text { 1. Os motores da inovação sustentável são as marcas líderes globais as quais } \\
\text { afirmam ser entidades de negócios socialmente responsáveis; } 2 \text {. A eficiência e a } \\
\text { estética estimulam o valor da marca, mais quando a inovação percebida é alta do que } \\
\text { quando é baixa. O estudo de brand equity e inovação tem tradicionalmente focado no } \\
\text { produto e menos nos serviços. }\end{array}$ \\
\hline 7.1.3 & $\begin{array}{l}\text { Desenhos } \\
\text { ind. p/ } \\
\text { origem/bi }\end{array}$ & $\begin{array}{l}\mathrm{N}^{\circ} \text { de desenhos } \\
\text { contidos no desenho } \\
\text { industrial solicitado de } \\
\text { residente e } \\
\text { apresentados em um } \\
\text { escritório } \\
\text { nacional/regional. }\end{array}$ & $\begin{array}{l}\text { 1. Aversa } \text { et al. } \\
(2017) ; \text {. Vivaldi, } \\
\text { G. A. D., Portugal } \\
\text { Júnior, P. S. \& } \\
\text { Camarini, G. } \\
(2021) .\end{array}$ & $\begin{array}{l}\text { 1. A nanotecnologia, o desenvolvimento sustentável e o desenho industrial definem } \\
\text { uma ampla área de interseção levando grande potencial para a aplicação de } \\
\text { verdadeiras inovações; } 2 \text {. Analisa a relação entre a propriedade intelectual (com base } \\
\text { nas patentes de invenção PI, nos modelos de utilidade MU, no desenho industrial DI } \\
\text { e nas marcas M) e o crescimento econômico refletido no PIB. A pesquisa mostrou } \\
\text { uma forte relação entre a PI e o crescimento econômico. }\end{array}$ \\
\hline 7.1.4 & $\begin{array}{l}\text { TIC e } \\
\text { criação } \\
\text { modelo } \\
\text { organizaci } \\
\text { onal }\end{array}$ & $\begin{array}{l}\text { Média das respostas à } \\
\text { pergunta: "Em seu } \\
\text { país, até que ponto as } \\
\text { TICs permitem novos } \\
\text { modelos } \\
\text { organizacionais dentro } \\
\text { empresas? }\end{array}$ & $\begin{array}{l}\text { 1. García-Alvarez } \\
(2015) ; 2 \text {. Soto- } \\
\text { Acosta \& } \\
\text { Cegarra-Navarrro } \\
(2016)\end{array}$ & $\begin{array}{l}\text { 1. As TICs influenciam os processos de gestão do conhecimento nas organizaçães e } \\
\text { sua influência na inovação e co-aprendizagem com abordagem econômica, motivo } \\
\text { pelo qual é assunto de particular relevância nas empresas para obtenção de vantagens } \\
\text { competitivas. } 2 \text {. Há novas perspectivas na utilização das TIC no conhecimento } \\
\text { gerencial nas organizações ao facilitar a aquisição, a criação e o compartilhamento } \\
\text { da inteligência coletiva, a absorção do crescente conhecimento acadêmico através da } \\
\text { rede de promoção da inovação e mudanças econômicas e organizacionais. }\end{array}$ \\
\hline 7.2.1 & $\begin{array}{l}\text { Exp. } \\
\text { prod.cultu } \\
\text { rais - } \\
\text { criativos }\end{array}$ & $\begin{array}{l}\text { Se refere às } \\
\text { exportações de } \\
\text { serviços criativos } \\
\text { como porcentagem } \\
\text { das exportações totais. }\end{array}$ & $\begin{array}{l}\text { 1. Moore (2014); } \\
\text { 2. Gouveia \& } \\
\text { Vora (2016). }\end{array}$ & $\begin{array}{l}\text { 1. Inovação e criatividade são termos amplamente usados e o conceito de Economia } \\
\text { Criativa; } 2 \text {. Embora o comércio global continue a crescer de forma constante, o papel } \\
\text { dos bens e serviços criativos tem sido cada vez mais reconhecido por sua } \\
\text { contribuição para o desenvolvimento e crescimento econômico. Os mercados de } \\
\text { exportação são um componente importante de bens e serviços criativos. }\end{array}$ \\
\hline 7.2.2 & $\begin{array}{l}\text { Filmenaci } \\
\text { onaL } \\
\text { longa }\end{array}$ & $\begin{array}{l}\mathrm{N}^{\circ} \text { de longas p/milhão } \\
\text { de hab. de } 15 \text { a } 69 \\
\text { anos, c/ duração }>= \\
60\end{array}$ & $\begin{array}{l}\text { 1. Efrat }(2014) ; 2 . \\
\text { Jones \& Davis } \\
(2000)\end{array}$ & $\begin{array}{l}\text { 1. A maioria dos aspectos culturais demonstra um impacto forte e duradouro sobre a } \\
\text { tendência de inovar no nível nacional; } 2 \text {. A cultura afeta a inovação e deve ser } \\
\text { explicitamente considerada como um fator que orienta a decisão de localização de } \\
\text { inovadoras estrangeiras. }\end{array}$ \\
\hline 7.2.3 & $\begin{array}{l}\text { Mercado } \\
\text { de } \\
\text { entreteni } \\
\text { mento e } \\
\text { mídias }\end{array}$ & $\begin{array}{l}\text { Análises globais e } \\
\text { previsões de } 5 \text { anos de } \\
\text { consumo e gastos com } \\
\text { publicidade em } 53 \\
\text { territórios p/ } 14 \\
\text { segmentos } \\
\text { entretenimento e } \\
\text { mídia. }\end{array}$ & $\begin{array}{l}\text { 1. Kacou (2015); } \\
\text { 2. Arakji \& Lang } \\
\text { (2007). }\end{array}$ & $\begin{array}{l}\text { 1. A indústria de mídia e entretenimento (M\&E) fornece produtos e serviços que } \\
\text { servem para manter os consumidores envolvidos e atualizados. É um setor } \\
\text { estratégico chave com alto potencial para diversificação de comércio e investimento, } \\
\text { criação de empregos, criação de significado compartilhado e influência do discurso } \\
\text { público; 2. Examinam formas de colaboração entre produtores e consumidores que } \\
\text { estão surgindo no espaço do entretenimento digital e mostram como as empresas se } \\
\text { engajaram na terceirização de partes de seu design de jogos e processo de } \\
\text { desenvolvimento p/ redes digitais de consumo. }\end{array}$ \\
\hline 7.2.4 & $\begin{array}{l}\text { Produtos } \\
\text { importado } \\
\text { s e outras } \\
\text { mídias }\end{array}$ & $\begin{array}{l}\text { Produção de } \\
\text { periódicos diários e } \\
\text { mídias para ser fonte } \\
\text { primária escrita de } \\
\text { informações sobre } \\
\text { eventos, questões } \\
\text { internacionais, política } \\
\text { etc. }\end{array}$ & $\begin{array}{l}\text { 1. Chirumalla, } \\
\text { Oghazic \& Parida } \\
(2018) ; 2 . \\
\text { Cunningham at al. } \\
(2004) \text {. }\end{array}$ & $\begin{array}{l}\text { Há a necessidade de uma melhor compreensão atualizada das estratégias de } \\
\text { engajamento de mídia social na facilitação do marketing e interfaces de P\&D. A } \\
\text { literatura atual oferece pouca orientação para o desenvolvimento de seus usos } \\
\text { estratégicos. Mas, mesmo assim, as empresas empregam cada vez mais mídias } \\
\text { sociais para inovação; } 2 \text {. Questionam a abordagem de um sistema de inovação para } \\
\text { as indústrias de conteúdo criativo e, especialmente, digital, e destacam a sua } \\
\text { importância porque tal abordagem pode abrir um território político dinâmico e } \\
\text { central que tem sido preservado pela ciência, engenharia e tecnologia em todo o } \\
\text { mundo. }\end{array}$ \\
\hline
\end{tabular}




\begin{tabular}{|c|c|c|c|c|}
\hline 7.2.5 & $\begin{array}{l}\text { Exportaçã } \\
\text { o } \\
\text { produtos } \\
\text { criativos }\end{array}$ & $\begin{array}{l}\text { Corresponde ao valor } \\
\text { total das exportações } \\
\text { de produtos criativos } \\
\text { em US\$ correntes } \\
\text { como percentagem do } \\
\text { comércio total. }\end{array}$ & $\begin{array}{l}\text { 1. Cassiman \& } \\
\text { Martínes (2007); } \\
\text { 2. Aghion et al. } \\
\text { (2018). }\end{array}$ & $\begin{array}{l}\text { 1. A inovação de produto é um motor muito importante das exportações para } \\
\text { pequenas firmas não exportadoras. A inovação de produto, ao invés da inovação de } \\
\text { processo, afeta a produtividade da empresa, o que, por sua vez, induz as empresas a } \\
\text { escolherem o mercado de exportação; } 2 \text {. O efeito dos choques nas exportações sobre } \\
\text { a inovação aumenta o tamanho do mercado e, portanto, os incentivos à inovação para } \\
\text { todas as empresas, e intensifica a concorrência à medida que mais empresas entram } \\
\text { nas exportações. }\end{array}$ \\
\hline 7.3.1 & $\begin{array}{l}\text { Domínios } \\
\text { genéricos } \\
\text {-alto nível }\end{array}$ & $\begin{array}{l}\text { Domínios de nível } \\
\text { superior (TLDs) } \\
\text { mantidos pela internet } \\
\text { para atribuição de } \mathrm{n}^{0} \mathrm{p} / \\
\text { uso na Internet. }\end{array}$ & $\begin{array}{l}\text { 1. Loet (2001); } 2 \text {. } \\
\text { Mueller (2000). }\end{array}$ & $\begin{array}{l}\text { 1. As terminações na internet possibilitam melhor classificação nas pesquisas e no } \\
\text { trato com o banco de dados; } 2 \text {. Examina os conflitos de direitos de propriedade sobre } \\
\text { nomes de domínio da Internet que surgiram quando a Internet foi comercializada e } \\
\text { privatizada. Os eventos são interessantes porque são exemplos de inovação } \\
\text { institucional em escala internacional catalisada por mudança tecnológica. }\end{array}$ \\
\hline 7.3.2 & $\begin{array}{l}\text { TLD de } \\
\text { código do } \\
\text { país }\end{array}$ & $\begin{array}{l}\text { Dados coletados do } \\
\text { registro responsável p/ } \\
\text { cada ccTLD e } \\
\text { representa o número } \\
\text { total de registros do } \\
\text { ccTLD. }\end{array}$ & $\begin{array}{l}\text { 1. Ferreira (2004); } \\
\text { 2. Awoleye et al. } \\
(2013) \text {. }\end{array}$ & $\begin{array}{l}\text { 1. A concentração ou dispersão espacial dos domínios de primeiro nível parece ser } \\
\text { um bom instrumento para analisar a dinâmica info-estrutural e o desenvolvimento } \\
\text { econômico de um território. Ao mesmo tempo, mostra que as tecnologias da } \\
\text { informação são essenciais para a inovação e a vantagem competitiva: } 2 \text {. Na análise } \\
\text { do sistema financeiro precário da Nigéria, observa que nenhum dos bancos usa } \\
\text { domínio de primeiro nível com código de país (ccTLD) para seus sites. }\end{array}$ \\
\hline 7.3.3 & $\begin{array}{l}\text { Edições } \\
\text { Wikipedia } \\
\text { /mi hab. }\end{array}$ & $\begin{array}{l}\text { Dados das economias } \\
\text { com mais de } 100.000 \\
\text { edições em } \\
\text { 2019/milhão de } \\
\text { habitantes de } 15 \text { a } 69 \\
\text { anos. }\end{array}$ & $\begin{array}{l}\text { 1. Baytiyeh \& } \\
\text { Pfaffman (2010); } \\
\text { 2. Chesbrough \& } \\
\text { Melissa (2007). }\end{array}$ & $\begin{array}{l}\text { 1. As pessoas que alimentam a Wikipedia, em geral, estão interessadas em aprender } \\
\text { novas técnicas de tecnologia relacionadas, novos recursos e praticar novas } \\
\text { ferramentas de forma a terem satisfação que torna o processo mais envolvente; } 2 \text {. } \\
\text { Para garantir transparência no processo da inovação aberta, a Wikipedia mantém } \\
\text { registro de todas as entradas de dados e os seus editores para que a comunidade } \\
\text { possa ver as origens das entradas e a história de postagens para possível checagem de } \\
\text { informações. }\end{array}$ \\
\hline 7.3.4 & $\begin{array}{l}\text { Criação } \\
\text { aplicativo } \\
\text { móveis }\end{array}$ & $\begin{array}{l}\text { Diz respeito aos } \\
\text { downloads globais de } \\
\text { aplicativos móveis, } \\
\text { por origem da sede do } \\
\text { desenvolvedor. }\end{array}$ & $\begin{array}{l}\text { 1. Siqueira Neto } \\
(2018) ; 2 . \text { Martin } \\
\text { et al. }(2017) \text {. }\end{array}$ & $\begin{array}{l}\text { 1. Nas organizações bancárias a utilização de aplicativos móveis é essencial para a } \\
\text { manutenção de parte dos clientes, já que hoje estes realizam suas funções } \\
\text { exclusivamente através de canais remotos; } 2 \text {. Os dispositivos móveis apresentam um } \\
\text { avanço na forma de se comunicar, além englobarem as principais tecnologias de } \\
\text { comunicação em somente um dispositivo: internet, GPS, e-mail, SMS, redes sociais } \\
\text { e aplicativos. }\end{array}$ \\
\hline
\end{tabular}

Fonte: Autores (2022).

\section{Considerações Finais}

Se verificou nos extratos das publicações constantes da Quadro 1 na seção anterior que, do ponto de vista acadêmico, a utilização dos indicadores que compõem o GII 2020 é justificável. Este resultado, contribui no esforço de validação e geração de credibilidade da métrica e complementa, de certa forma, os resultados da auditoria externa independente, realizada anualmente pelo European Union Joint Research Center, a qual é voltada para a avaliação quantitativa da construção do Índice.

Observou-se ainda que nem sempre há clareza na relação direta entre o indicador e o processo inovativo, o que indica haver espaço para pesquisas mais densas e detalhadas relacionadas a estes indicadores.

As relações verificadas não expressam o grau da contribuição de cada indicador no escore do Índice, o que indica ser uma lacuna de pesquisa, no caso, de cunho quantitativo já que se avaliaria o impacto de cada um dos indicadores no escore do Índice, e assim verificar o grau de suas contribuições no processo inovativo.

\section{Referências}

Abeyasinghe, R. \& Seeborg, M. (2004). Democracy, political stability, and developing country growth: theory and evidence. The John Wesley Powell student research conference. Department University. https://digitalcommons.iwu.edu/cgi/viewcontent.cgi?article=1752\&context=jwprc 
Research, Society and Development, v. 11, n. 3, e19911326092, 2022

(CC BY 4.0) | ISSN 2525-3409 | DOI: http://dx.doi.org/10.33448/rsd-v11i3.26092

Acharya, V. V., Baghai, R. P. \& Subramanian, K. V. (2013). Labor Laws and Innovation. The Journal of Law and Economics Volume 56, Number 4

Acemoglu, D. \& Akcigit, U. (2006). State-Dependent Intellectual Property Rights Policy.NBER, Working Paper 12775. DOI 10.3386/w12775. https://www.nber.org/papers/w12775

Acosta, B., Padula, A. D. \& Wegner, D. (2009). Empresas que possuem certificações são mais inovadoras? Uma análise no setor de produção de rosas no equador $\quad$ ANAIS SIMPOL 2009, https://www.researchgate.net/profile/Byron-Acosta2/publication/266469279_EMPRESAS_QUE_POSSUEM_CERTIFICACOES_SAO_MAIS_INOVADORAS_UMA_ANALISE_NO_SETOR_DE_PRODU CAO_DE_ROSAS_NO_EQUADOR/links/5a1dc51c0f7e9b9d5effa868/EMPRESAS-QUE-POSSUEM-CERTIFICACOES-SAO-MAIS-INOVADORASUMA-ANALISE-NO-SETOR-DE-PRODUCAO-DE-ROSAS-NO-EQUADOR.pdf

Aghion, P., Bergeaud, A., Lequien, M. \& Melitz, M. C. (2018). The impact of exports on innovation: theory and evidence. Working Paper 24600. http://www.nber.org/papers/w24600

Akinwale, Y. O., Dada, A. D., Oluwadare, A. J., Jesuleye, O. A. \& Siyanbola. W. O. (2012). Understanding the Nexus of R\&D, Innovation and Economic Growth in Nigeria. National Centre for Technology Management, Obafemi Awolowo University, Ile-ife, Nigeria Correspondence: Yusuf O. Akinwale, National Centre for Technology Management, Obafemi Awolowo doi:10.5539/ibr.v5n11p187 URL: http://dx.doi.org/10.5539/ibr.v5n11p187.

Amon-Há, R., Arruda, R. D., Bezerra, J. F. \& Leitão, N. P. (2019). Índice de Inovação Global - Uma análise da trajetória brasileira entre os anos de 2007 a 2018. https://www.anpec.org.br/encontro/2019/submissao/files_I/i9-30bba0c8bcf2bb63bb77c7321c333b7f.pdf

Arakji, R. Y. \& Lang, K. R. (2007). Digital Consumer Networks and Producer-Consumer Collaboration: Innovation and Product Development in the Digital Entertainment Industry," 2007 40th Annual Hawaii International Conference on System Sciences (HICSS'07), 2007, pp. 211c-211c, doi:10.1109/HICSS.2007.173.

Arbix, G. (2010). Estratégias de inovação para o desenvolvimento. Tempo Social - Revista de Sociologia da USP, 22, https://doi.org/10.1590/S010320702010000200009

Archer, L. T., Sharma, P. \& Su, Jen-Je (2020) Do credit constraints always impede innovation? Applied Economics. https://www.tandfonline.com/doi/abs/10.1080/00036846.2020.1751049

Arif, I. - (2017) Three Essays on International Mobility and Economic Development, The Research Reportory - West Virginia University.

Aslesen, H. W. \& Isaksen, A (2007) New perspectives on knowledge-intensive services and innovation, Geografiska Annaler: Series B, Human Geography, 89:sup1, 45-58, https://www.tandfonline.com/action/showCitFormats?doi=10.1111\%2Fj.1468-0467.2007.00259.x

Asongu, S., Boateng, A., \& Akamavi, R. K. (2016). Mobile Phone Innovation and Inclusive Human Development: Evidence from Sub-Saharan Africa. African Governance and Development Institute WP/16/027, Available at SSRN: https://ssrn.com/abstract=2822103.

Atkinson, R. \& Mayo, M. (2010). Refueling the u.s. innovation economy: fresh Approaches to Science, Technology, Engineering and Mathematics (STEM) Education. Information Technology and Innovation Foundation. https://eric.ed.gov/?id=ED521736.

Audy, J. (2017) A inovação, o desenvolvimento e o papel da Universidade. Faculdade de Informática, Pontifícia Universidade Católica do Rio Grande do Sul, Porto Alegre, Rio Grande do Sul, Brasil. Estudos Avançados 31, https://www.scielo.br/j/ea/a/rtKFhmw4MF6TPm7wH9HSpFK/?format=pdf\&lang=pt

Aversa, R., Petrescu, R. V., Petrescu, F. I. \& Apicella, A. (2017). Biomimetic and Evolutionary Design Driven Innovation in Sustainable Products Development (November 20, 2017). American Journal of Engineering and Applied Sciences 2016, 9(4), Available at SSRN: https://ssrn.com/abstract=3074457

Barbieri, J. C., Vasconcelos, I. F. G., Tales, A. \& Vasconcelos, F. C. (2010). Inovação e sustentabilidade: novos modelos e proposições. RAE • São Paulo, v. 50 (2), abr./jun. 2010 • 146-154. https://www.scielo.br/j/rae/a/yfSJ69NTb8jcHSYr3R9bztJ/?lang=pt\&format=pdf

Bastos, G. (2016). Gestão da inovação tecnológica: fundamentos e diretrizes - Rio de Janeiro, RJ: Logike Associados® S/C Ltda. https://glaudsonbastos.com.br/images/documentos/Gesto-da-Inovao-Tecnolgica---Fundmentos-e-Diretrizes---Glaudson-Bastos.pdf

Baytiyeh, H. \& Pfaffman. J. (2010). Volunteers in Wikipedia: Why the Community Matters. Journal of Educational Technology \& Society 13(2): 128-40. http://www.jstor.org/stable/jeductechsoci.13.2.128.

Belloc, F. (2013). Law, finance and innovation: the dark side of shareholder protection. Cambridge Journal of Economics, Volume 37(4), July 2013, pp. 863888, https://doi.org/10.1093/cje/bes068

Beneito, P. (2006). The innovative performance of in-house and contracted R\&D in terms of patents and utility models. Research Policy, volume 3 (4), pp. 502-517, ISSN 0048-7333,https://doi.org/10.1016/j.respol.2006.01.007. (https://www.sciencedirect.com/science/article/pii/S0048733306000400)

Bhargava, S. (2019). Ease of Doing Business Index of India: Paving the Road Ahead. International Journal of Multidisciplinary, Volume 04 (6), ISSN: 24553085 (Online). www.rrjournals.com

Biryukova, O.V. \& Matiukhina, A.I. (2019) ICT Services Trade in the BRICS Countries: Special and Common Features. J Knowl Econ 10, 1080-1097 (2019). https://doi.org/10.1007/s13132-017-0517-6. https://link.springer.com/article/10.1007/s13132-017-0517-6\#citeas

Boone, J. (2001). Intensity of competition and the incentive to innovate. International Journal of Industrial Organization. Volume 19 (5), pp. 705-726, ISSN 0167-7187. https://doi.org/10.1016/S0167-7187(00)00090-4. (https://www.sciencedirect.com/science/article/pii/S0167718700000904)

Boraha, D., Malikb, K. \& Massinib, S. (2019). Are engineering graduates ready for R\&D jobs in emerging countries? - University of Liverpool Management School, UK, Research Policy, Volume 48 (9). https://www.sciencedirect.com/science/article/pii/S004873331930157X 
Borensztein, E., De Gregorio, J. \& Lee, J-W. (1998). How does foreign direct investment affect economic growth? Journal of International Economics,

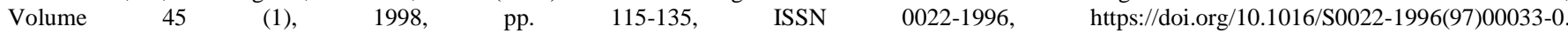
(https://www.sciencedirect.com/science/article/pii/S0022199697000330)

Bratsberg, B. \& Terrell, D. (2002). School quality and returns to education of U.S. immigrants. Economic Inquiry, 40 (2), 177-198. https://doi.org/10.1093/ei/40.2.1

Broome, M. (2000). Integrative literature reviews for the development of concepts. In: Rodgers BL, Knafl KA. Concept development in nursing: foundations, techniques, and applications. 2nd Philadelphia. https://www.researchgate.net/publication/238248432_Integrative_literature_reviews_for_the_development_of_concepts

Brown, J. R., Martinsson, G. \& Petersen, B. C. (2013). Law, Stock Markets, and Innovation. The Journal of Finance, volume 68 (4), pp. 1517-1549. https://doi.org/10.1111/jofi.12040

Burlamaqui, L. \& Proença, A. (2009). Inovação, Recursos e Comprometimento: Em Direção a uma Teoria Estratégica da Firma. Revista Brasileira De Inovação, 2(1), 79-110. https://doi.org/10.20396/rbi.v2i1.8648869

Carli, P. M., Oliveira, L. H., \& Dias, E. C. ( 2013). Impacto da certificação Rainforest Alliance na gestão de uma propriedade de café no sul de Minas Gerais. VIII Simpósio de Pesquisa dos Cafés do Brasil, 25 a 28 de novembro de 2013, Salvador - BA

Carlisle, Y., \& McMillan, E. (2006) Innovation in organizations from a complex adaptive systems perspective. Emergence-Mahwah-Lawrence-Erlbaum, v. 8 (1), p. 2, 2006. http://www.8wekyb3d8bbwe/TempState/Downloads/InnovOrgsCompexSyst\%20(11).pdf

Carrion-Flores, C. \& Innes, R. (2009). Environmental innovation and environmental performance. Journal of Environmental Economics and Management, $\begin{array}{llllll}\text { Volume } & 59 & (1), & \text { pp. } & 27-42, & \text { ISSN }\end{array}$ (https://www.sciencedirect.com/science/article/pii/S0095069609000667)

Cassiman, B. \& Martínez-Ros, E. $\quad$ (2007). Product Innovation and $\quad$ Exports. https://citeseerx.ist.psu.edu/viewdoc/download?doi=10.1.1.616.3672\&rep=rep1\&type=pdf

Chadee, D. \& Roxas, B. (2013). Institutional environment, innovation capacity and firm performance in Russia. Perspectives on International Business, Volume 9 (1-2), pp. 19-39(21). Emerald Group Publishing Limited. DOI: https://doi.org/10.1108/17422041311299923

Charmes, J., Gault, F. \& Wunsch-Vincent, S. (2018), "Measuring innovation in the informal economy - formulating an agenda for Africa". Journal of Intellectual Capital, Vol. 19 (3), pp. 536-549. https://doi.org/10.1108/JIC-11-2016-0126

Chau, V. S. \& Quire, C. (2018) Back to the future of women in technology: insights from understanding the shortage of women in innovation sectors for managing corporate foresight. Technology Analysis \& Strategic Management, 30:6, 747-764, DOI: 10.1080/09537325.2017.1376046. https://www.tandfonline.com/action/showCitFormats?doi=10.1080\%2F09537325.2017.1376046

Chen, X. \& Moul, C. C. (2014). Disease or utopia? Testing Baumol in education. Economics Letters, volume 122 (2), pp. 220-223, ISSN 0165-1765, https://doi.org/10.1016/j.econlet.2013.11.032.(https://www.sciencedirect.com/science/article/pii/S0165176513005260)

Chen, Z., Zhang, J. \& Zheng, W. (2017). Import and innovation: Evidence from Chinese firms. European Economic Review, volume 94, pp. 205-220. ISSN 0014-2921, https://doi.org/10.1016/j.euroecorev.2017.02.008. (https://www.sciencedirect.com/science/article/pii/S0014292117300338)

Chesbrough, H. W. \& Melissa, M. (2007). Appleyard. Open Innovation and Strategy. California Management Review. Volume: 50 (1), pp.(s): 57-76. https://doi.org/10.2307/41166416

Chiarini, T. \& Gonçalves Silva, A. L. (2016) Intellectual property rights and innovation system: some lessons from Brazil. UNICAMP - State University of Campinas, Campinas, Brazil. National Institute of Technology, Rio de Janeiro, Brazil. https://doi.org/10.1504/IJIL.2016.079066. https://www.inderscienceonline.com/doi/abs/10.1504/IJIL.2016.079066.

Chirumalla, K., Oghazic, P. \& Parida, V. (2018). Social media engagement strategy: Investigation of marketing and R\&D interfaces in manufacturing industry, Industrial Marketing Management, $\quad$ Volume 2018 , 74, https://www.sciencedirect.com/science/article/abs/pii/S0019850117301396

Cohen, L., Diether, K. \& Malloy, C. (2013). Misvaluing Innovation. The Review of Financial Studies, Volume 26 (3),pp. 635-666, https://doi.org/10.1093/rfs/hhs183

Colgan, C. S. \& Baker, C. (2003). A Framework for Assessing Cluster Development. Economic Development Quarterly, volume 17 (4), pp. $352-366$. University of Southern Maine. https://doi.org/10.1177/0891242403256667.

Coscrato, G., Pina, J. C. \& Mello, D. F. (2010). Utilização de atividades lúdicas na educação em saúde: uma revisão integrativa da literatura. Acta Paulista de Enfermagem [online]. 2010, v. 23 (2), pp. 257-263. https://doi.org/10.1590/S0103-21002010000200017.

Cozza, C., Malerba, F., Mancusi, M. L., PeranI, G. \& Vezzulli, A. (2012). Innovation, profitability and growth in medium and high-tech manufacturing industries: evidence from Italy. Applied Economics, 44:15, 1963-1976, DOI: 10.1080/00036846.2011.556594. https://www.tandfonline.com/doi/abs/10.1080/00036846.2011.556594

Cunningham, S., Cutler, T., Hearn, G., Ryan, M. \& Keane, . (2004). An Innovation Agenda for the Creative Industries: Where is the R\&D? Research Article, volume: 112 (1), pp.(s): 174-185. https://doi.org/10.1177/1329878X0411200114. https://journals.sagepub.com/doi/abs/10.1177/1329878X0411200114

Dalle Nogare, G. E. (2015). A relação entre inovação, mercado acionário e crescimento econômico. Programa de Pós-Graduação em Engenharia de Produção (UFSM). http://repositorio.ufsm.br/handle/1/8368 
Delgado, D. M. \& Pessoa, M. B. D. (2010). A Educação Superior no contexto da inovação como fator estratégico no setor produtivo: um estudo empírico aplicado a cenários regionais. Revista on line de Política e Gestão Educacional, Araraquara, n. 8, pp. 1-20, 2010. DOI: 10.22633/rpge.v0i8.9262. Disponível em: https://periodicos.fclar.unesp.br/rpge/article/view/9262. Acesso em: 23 set. 2021.

Dhrifi, A. (2015). Foreign direct investment, technological innovation and economic growth: empirical evidence using simultaneous equations model. International Review of Economics 62, 381-400 (2015). https://doi.org/10.1007/s12232-015-0230-3

Dias, R. B. (2007). A política cientifica e tecnológica latino-americana: relações entre enfoques teóricos e projetos políticos. Universidade Estadual de Campinas, São Paulo. http://repositorio.unicamp.br/handle/REPOSIP/286697

DOING BUSSINESS - WORLD BANK (2017). https://portugues.doingbusiness.org/pt/data/exploretopics/starting-a-business

DOING BUSSINESS - $\quad$ WORLD BANK $\quad$ (2018). https://www.doingbusiness.org/en/reports/global-reports/doing-business2018\#: :text=Doing\%20Business $\% 202018 \% 3$ A $\% 20$ Reforming $\% 20$ to $\% 20$ Create $\% 20 \mathrm{Jobs} \% 2 \mathrm{C} \% 20$ a,enhance\%20business $\% 20$ activity $\% 20$ and $\% 20$ those $\% 20$ t hat $\% 20$ constrain $\% 20$ it.

Dosi, G., Freeman, C., Nelson, R., Silverberg, G. \& Soete, L. (1988). Technical change and economic theory. London: Printer Publishers. http://www.lem.sssup.it/WPLem/files/dosietal_1988_outline.pdf

Dostie, B. (2017) The Impact of Training on Innovation. IRL Review. https://doi.org/10.1177/0019793917701116, https://journals.sagepub.com/doi/abs/10.1177/0019793917701116.

Dutta, S. \& Lanvin, B. (2016) The Global Innovation Index 2013. The Local Dynamics of Innovation. http://repositorio.colciencias.gov.co:8080/bitstream/handle/11146/242/1558-DUTTA_2013_THE_GLOBAL_INNOV.PDF?sequence=1\&isAllowed=y

Dutta, S., Lanvin, B. \& Wunsch-Vincent, S. (2020). Global Innovatios Index, $13^{\circ}$ edition, Who Will Finance Innovation? University of Cornell - SC Johnson College of Business, World Intelectual Property Organization - WIPO, e Institut Européen d'Administration des Affaires - INSEAD

Efrat, K. (2014). The direct and indirect impact of culture on innovation, Technovation, Volume 34, Issue 1, pp. 12-20, ISSN 0166-4972. https://doi.org/10.1016/j.technovation.2013.08.003. (https://www.sciencedirect.com/science/article/pii/S0166497213001028)

Ekicia, S. Ö., Kabakb, Ö. \& Ülengin, F. (2019). Improving logistics performance by reforming the pillars of Global Competitiveness Index. Transport Policy,

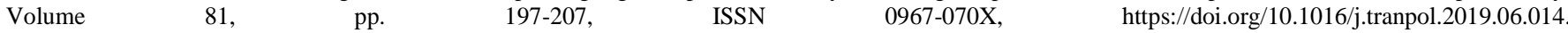
(https://www.sciencedirect.com/science/article/pii/S0967070X18305456)

Erkkilä, T. \& Piironen, O. (2020). Trapped in university rankings: bridging global Competitiveness and local innovation. International Studies in Sociology of Education, 29:1-2, 38-60, DOI: 10.1080/09620214.2019.1634483

Falk, M. (2009). High-tech exports and economic growth in industrialized countries, Applied Economics Letters, 16:10, 1025-1028, DOI: 10.1080/13504850701222228. https://www.tandfonline.com/doi/abs/10.1080/13504850701222228

Ferraris, A., Devalle, A., Ciampi, F. \& Couturier, J. (2019). Are global R\&D partnerships enough to increase a company's innovation performance? The role of search and integrative capacities. Technological Forecasting and Social Change, Volume 149, ISSN 0040-1625, (https://www.sciencedirect.com/science/article/pii/S0040162519304330)

Ferreira, J. (2004) Internet Geography: Spaces of Innovation. Proceedings of the ERSA Summer Institute. http://hdl.handle.net/10362/4374,

Figueiredo, P. N. (2006), "Capacidade tecnológica e Inovação em Organizações de Serviços Intensivos em Conhecimento: evidências de institutos de pesquisa em Tecnologias da Informação e da Comunicação (TICs) no Brasil”. Revista Brasileira da Inovação, v. 5 (2), p. 403-454. https://periodicos.sbu.unicamp.br/ojs/index.php/rbi/article/view/8648935

FMI (2019). World Economic Outlook Database, outubro de 2019 (PPC \$ PIB). (https://eikon.thomsonreuters.com/index.html), https://www.imf.org/external/pubs/ft/weo/2019/02/weodata/index.aspx

Frankhauser, S., Sehlleier, F. \& Stern, N. (2008). Climate change, innovation and jobs. Climate Policy, 8:4, 421-429, DOI: 10.3763/cpol.2008.0513. https://www.scielo.br/scielo.php?script=sci_nlinks\&ref=000112\&pid=S0103-4014201300010000800010\&lng=en

Freeman, C. (1995) "The 'National System of Innovation' in Historical Perspective". Cambridge Journal of Economics 19 (1), pp. 5-24. https://www.researchgate.net/publication/5207975_The_'National_System_of_Innovation'_in_Historical_Perspective

Gao, X. \& Guan, J. (2009). A scale-independent analysis of the performance of the Chinese innovation system. Journal of Informetrics, volume 3 (4), pp. 321 331. ISSN 1751-1577, https://doi.org/10.1016/j.joi.2009.04.004. (https://www.sciencedirect.com/science/article/pii/S1751157709000364)

García-Álvarez, M, T. (2015). Analysis of the effects of ICTs in knowledge management and innovation: The case of Zara Group, Computers in Human Behavior, v. 51, part B, pp. 994-1002, ISSN 0747-5632, https://doi.org/10.1016/j.chb.2014.10.007.

Gault, F. (2018). Defining and measuring innovation in all sectors of the economy, Research Policy, Volume 47, Issue 3, pp. 617-622, ISSN 0048-7333, https://doi.org/10.1016/j.respol.2018.01.007. (https://www.sciencedirect.com/science/article/pii/S0048733318300076)

Gibson, C. \& Klocker, N. (2004). Academic publishing as 'creative' industry, and recent discourses of 'creative economies': some critical reflections. Royal Geographical Society, volume 36 (4, )pp. 423-434. https://doi.org/10.1111/j.0004-0894.2004.00242.x

GCI (2019). Global Competitiveness Report 2019: How to end a lost decade of productivity growth. https://www.weforum.org/reports/how-to-end-a-decadeof-lost-productivity-growth 
GII (2020). Global Innovation Index (2020). Who Will Finance Innovation? Cornell University, INSEAD, WIPO. https://www.wipo.int/publications/en/details.jsp?id=4514\#: :text=The\%20Global\%20Innovation\%20Index\%202020\%20provides\%20detailed\%20metrics,incl uding $\% 20$ political $\% 20$ environment $\% 2 \mathrm{C} \% 20$ education $\% 2 \mathrm{C} \% 20$ infrastructure\%20and $\% 20$ business $\% 20$ sophistication

Girma, S., Gong, Y. \& Görg, H. (2008) Foreign Direct Investment, Access to Finance, and Innovation Activity in Chinese Enterprises. The World Bank Economic Review, Volume 22, Issue 2, 2008, pp. 367-382, https://doi.org/10.1093/wber/lhn009.

Gomes, W. (2005). A democracia digital e o problema da participação civil na decisão política. Revista Fronteiras: estudos midiáticos. Vol. VII no 3, pp. 214222. http://www.revistas.unisinos.br/index.php/fronteiras/article/view/6394

Gregory, S. (2008). Intellectual Property Rights and South Africa's Innovation Future. Development through Trade. South African Institute of International Affaires. University of the Witwatersrand, Johannesburg, South Africa. https://saiia.org.za/wp-content/uploads/2013/06/23-dttp_rep_23_gregory.pdf

Griffith, R. \& MaCartney, G. (2014). Employment Protection Legislation, Multinational Firms and Innovation. The Review of Economics and Statistics (2014) 96 (1): 135-150. https://doi.org/10.1162/REST_a_00348

Hanna N.K. (2010) ICT Services Industry for an Innovation Economy. In: Enabling Enterprise Transformation. Innovation, Technology, and Knowledge Management. Springer, New Nork, N. $\quad$ https://doi.org/10.1007/978-1-4419-1508-5_6 https://www.researchgate.net/publication/227096908_ICT_Services_Industry_for_an_Innovation_Economy

Hao, J. X., Ark, B. \& Ozyildirim, A. (2017) Signposts of innovation: a review o innovation metrics. Economics Program Working Paper Series. The Conference Board. https://papers.ssrn.com/Sol3/papers.cfm?abstract_id=2970648

Henry, C. \& Stiglitz, J. (2010) Intellectual Property, Dissemination of Innovation and Sustainable Development. https://doi.org/10.1111/j.17585899.2010.00048.x

Hirukawa, M. \& Ueda, M. (2011) Venture capital and innovation: which is first? Pacific Economic Review, volume16 (4), pp. 421-465. https://doi.org/10.1111/j.1468-0106.2011.00557.x

Hollanders, H. \& Van Cruysen, A. (2018). Rethinking the European Innovation Scoreboard: A New Methodology for 2008-2010. Pro Inno / Inno Metrics. https://eu.eustat.eus/elementos/ele0006100/Methodology_Report_EIS_2008-2010/inf0006199_e.pdf

Hovne, A. S., Hovne, B. \& Schott, T. (2014). Entrepreneurs' innovation benefitting from their education and training and from national policy and culture: a global study. International Journal of Entrepreneurship and Small Business, v. 23 (1-2). https://doi.org/10.1162/REST_a_00348.

Idota, H., Bunno, T. \& Tsuji, M. (2013). Covariance structure analysis of innovation and ICT use among Japanese innovative SMEs. 24th European Regional Conference of the International Telecommunications Society (ITS): "Technology, Investment and Uncertainty", Florence, Italy, 20th-23rd October, 2013. https://www.econstor.eu/handle/10419/88463

Ismail, N. W. (2013). Innovation and High-Tech Trade in Asian Countries. Department of Economics, Faculty of Economics and Management, University Putra Malaysia. ments/conferences/2013/malaysia-conference/normaz-wana-ismail.pdf

Jacobides, M. G., Cennamo, C. \& Gawe, A. International Conference on Recent Developments in Asian Trade Policy and Integration, 20th and 21st February, 2013 at the Kuala Lumpur Teaching Centre, the University of Nottingham Malaysia Campus. https://www.nottingham.ac.uk/gep/docu

(2018). Towards a theory of ecosystems. Strategic. Managment Journal, v. 39 (8), pp. 2255-2276. https://onlinelibrary.wiley.com/doi/full/10.1002/smj.2904

Jiao H., Koo C. K. \& Cui, Y. (2015). Legal environment, government effectiveness and firms' innovation in China: Examining the moderating influence of government ownership. Technological Forecasting \& Social Change, 96, pp. 15-24.

Jones, G. K. \& Davis, H. J. (2000). National Culture and Innovation: Implications for Locating Global R\&D Operations. MIR: Management International Review, v. 40 (1) 1 (2000 1st Quarter), pp. 11-39, Springer. https://www.jstor.org/stable/40835865

Jorgensen, D. W., \& Vu, K. M. (2005) Tecnologias de Informação e a Economia Mundial in Castellis, M. e Cardoso, G. (2005). A Sociedade em Rede: Do Conhecimento à Acção Política. https://www.academia.edu/download/31872966/A_SOCIEDADE_EM_REDE.pdf\#pp.=16.

Jungmittag, A. \& Welfens, P. J. J. (2017). Beyond EU-US Trade Dynamics: TTIP Effects Related to Foreign Direct Investment and Innovation. IZA Discussion Paper No. 10946, Available at SSRN: https://ssrn.com/abstract=3029817.

Kacou, E. (2015) Entertainment and Media. In: McNamee T., Pearson M., Boer W. (eds) Africans Investing in Africa. Palgrave Macmillan, London. https://doi.org/10.1057/9781137542809_12. https://link.springer.com/chapter/10.1057/9781137542809_12\#citeas.

Katz, J. S. (2006) Indicators for complex innovation systems. Research Policy, Volume 35 (7), pp. 893-909, ISSN 0048-7333, https://doi.org/10.1016/j.respol.2006.03.007. (https://www.sciencedirect.com/science/article/pii/S0048733306000825)

Kuenzer, A., Abreu, Z, Moura, C. B. \& Gomes, C. M. A. (2007). A articulação entre conhecimento tácito e inovação tecnológica: a função mediadora da educação. Revista Brasileira de Educação [online]. v. 12 (36), pp. 462-473.ISSN 1809-449X. https://doi.org/10.1590/S1413-247820070003000 06

Kurt, S. \& Kurt, Ü. (2015) - Innovation and Labour Productivity in BRICS Countries: Panel Causality and Co-integration, Procedia - Social and Behavioral Sciences, V. 3, pp. 1295-1302. https://www.sciencedirect.com/science/article/pii/S1877042815037751

Lahimer, N., Dash, S., \& Zaiter, M. (2013) Does Microfinance Promote Entrepreneurship and Innovation? A Macro Analysis. African Journal of Science, $\begin{array}{lllll}\text { Technology, Innovation and Development, } & 5: 1, & 19-29, & \text { DOI: } & 10.1080 / 20421338.2013 .782147 .\end{array}$ https://www.tandfonline.com/action/showCitFormats?doi=10.1080\%2F20421338.2013.782147 
Lee, S.M., Hwang, T. \& Choi, D. (2012), "Open innovation in the public sector of leading countries". Management Decision, Vol. 50 (1), pp. 147-162. https://doi.org/10.1108/00251741211194921,

Lee, Y.S. (2000). The Sustainability of University-Industry Research Collaboration: An Empirical Assessment. The Journal of Technology Transfer 25, pp. 111-133. https://doi.org/10.1023/A:1007895322042

Velho, L. (2007). O papel da formação de pesquisadores no sistema de inovação. Ciência e Cultura, 59 (4), 23-28. http://cienciaecultura.bvs.br/scielo.php?script=sci_arttext\&pid=S0009-67252007000400013\&lng=en\&tlng=en.

Lima, R. A., Velho, L. M. L. S., \& Farias, L. I. L. DE. (2012). Bibliometria e "avaliação" da atividade científica: um estudo sobre o índice h. Perspectiva em ciência da informação, v. 17 (3), p. 3-17. https://www.scielo.br/j/pci/a/RDCcbDdvjs3RhKHndm4vL4n/?format=pdf\&lang=pt

Li, M. (2011). Online government advisory service innovation through Intelligent Support Systems, Information \& Management, Volume 48 (1), pp. 27-36, ISSN 0378-7206, https://doi.org/10.1016/j.im.2010.12.002.

Loet, L. (2001). Indicators of innovation in a knowledgebased Economy. (CINDOC) Cybermetrics: International Journal of Scientometrics, Informetrics and Bibliometrics. E-ISSN: 1137-5019. http://hdl.handle.net/10261/174365

Lunardi, C. A. (2014). Educação e crescimento econômico no Brasil. FGV/EAESP. https://pesquisaeaesp.fgv.br/sites/gvpesquisa.fgv.br/files/publicacoes/cesar_augusto_lunardi.pdf

Ma, Z., Yu, M., Gao, C., Zhou, J. \& Yang, Z. (2015). Institutional constraints of product innovation in China: Evidence from international joint ventures. Journal of Business Research, Volume 68 (5). https://www.sciencedirect.com/science/article/abs/pii/S0148296314003051

Malmberg, C. (2005). Trademark statistics as innovation indicators?-A micro study. CIRCLE Electronic Working Paper Series, Vol. 2005 (17). CIRCLE, Lund University. https://portal.research.lu.se/ws/files/4643553/4407256.pdf.

Manders, B., Vries, H. J. \& Blind, K. (2016) ISO 9001 and product innovation: A literature review and research framework. Technovation, Volumes 48-49, 2016, $\quad$ pp. $\quad 41-55, \quad$ ISSN $\quad$ 0166-4972, $\quad$ https://doi.org/10.1016/j.technovation.2015.11.004 (https://www.sciencedirect.com/science/article/pii/S0166497215000784).

Martin, G., Luca, H. M., Schweitzer, J. S., Juliani. J. P. \& Ribeiro Junior, D. I. (2017). Inovação em bibliotecas: relato de experiência sobre a criação do Aplicativo vestbook sc. Revista ACB , v. 22 (3), pp. 596-610.: Biblioteconomia em Santa Catarina, Florianópolis https://dialnet.unirioja.es/servlet/articulo?codigo=6486338

Mattos, P. T. L. \& Abdal, A. (2010). Estados Unidos: mudanças jurídico-institucionais e inovação. https://d1wqtxts1 xzle7.cloudfront.net/58735111/2010_Mattos_e_Abdal_EUA_-_inovacao_e_mudancas_juridico_institucionais20190328-12604113r0gt5.pdf?1553800506=\&response-content-disposition=inline\%3B+filename\%3DEstados_Unidos_mudancas_juridico_institu.pdf\&Expires= 1618012955\&Signature=P12fJ041AKnnT7K1 yqwLg4OiWzdLwj8Hro o6nnoZhVQ02f8EYXa21m9lGi0NSArlhMYy9tz6TuMJPP0uMT1a1bjIAh68saVrgbyKC8FBe3BSCNvuOH2KThXdBLlyTY4vnipX KTYi7Kx83UDKwQircbyDcIPkEhgeJwmZVBPIJwE2H3TwvE2zIB4EWA6hHDRYJe 8ZGd zdoXVWAkQOehnZDJHigyHrHrfGY2ypLL w3IK0I2ABFLYjsOmCEZZTfzduN2oEU0jNxGNJpW7bo4I0Lr9GbvrF7ddKXaNEmat6wmMj3LukJOV6CG9 jVN Q5MAdMFI4gKxmuLOlSYkjg_\&Key-Pair-Id=APKAJLOHF5GGSLRBV4ZA

Mazzucato, M. (2014). O Estado empreendedor: Desmascarando o mito do setor público vs. setor privado. Portfolio-Penguin. Edição do Kindle. https://books.google.com.br/books?hl=pt-

BR\&lr=\&id=MnM0BQAAQBAJ\&oi=fnd\&pg=PT6\&dq=Mazzucato, $+2014 \&$ ots=5mA3vuPY8f\&sig=1JjDfFeu422K35TF8e8PEgpaduQ\#v=onepp.\&q=Mazzu cato $\% 2 \mathrm{C} \% 202014 \& \mathrm{f}=$ false.

Meyer, J. \& Rowan, B. (1991). Institutionalized organizations: formal structure as myth and ceremony. In: DIMAGGIO, P, POWELL, W. (Eds) The New Institutionalism in Organizational Analysis. Chicago: The University of https://www.scielo.br/j/rae/a/yfSJ69NTb8jcHSYr3R9bztJ/?format=pdf\&lang=en

Menezes Filho, N., Kotsumu, B. K., Lucchesi, A. \& Ferrario, M. (2014). Políticas de Inovação no Brasil. In: Policy Paper. Insper Instituto de Ensino e Pesquisa Centro de Políticas Públicas (CPP). https://www.insper.edu.br/wp-content/uploads/2018/09/Politicas-Inovacao-Brasil-CPP.pdf

Mendonça, S., Pereira, T. S. \& Godinho, M. M. (2004). Trademarks as an indicator of innovation and industrial change. Research Policy, volume 33 (9), pp. 1385-1404, ISSN 0048-7333, https://doi.org/10.1016/j.respol.2004.09.005. (https://www.sciencedirect.com/science/article/pii/S0048733304001222)

Miles, I. (2008). Knowledge-Intensive Services. Manchester Institute for Innovation Research, Manchester Business School, University of Manchester, UK. https://www.researchgate.net/profile/Ian-Miles-2/publication/264892391_Knowledge-Intensive_Services/links/542d36740cf29bbc126d2103/KnowledgeIntensive-Services.pdf

Moliner-Velázquez, B., Fuentes-Blasco, M. \& Gil-Saura, I. (2019). Effects of value and innovation on brand equity in retailing. J Brand Manag $26,658-674$. https://doi.org/10.1057/s41262-019-00159-5. https://link.springer.com/article/10.1057/s41262-019-00159-5\#citeas.

Moore, I. (2014) Cultural and Creative Industries Concept - A Historical Perspective. Procedia - Social and Behavioral Sciences, Volume 110, 2014, pp. 738746. ISSN 1877-0428, https://doi.org/10.1016/j.sbspro.2013.12.918. (https://www.sciencedirect.com/science/article/pii/S1877042813055584).

Morais, C. M. P. B. (2014). Práticas pedagógicas inovadoras com TIC. Repositório da Universidade de Lisboa Comunidades \& Colecções Instituto de Educação (IE), Inovação educativa, Tecnologias da informação e da comunicação, http://hdl.handle.net/10451/10660.

Moreira, N. V. A., Severo de Almeida, F. A., Matheus Cota. M. F. \& Sbragia, R. (2007). Revista de Gestão USP, São Paulo, v. 14, n. especial, p. 31-44. https://www.revistas.usp.br/rege/article/view/36580/39301

Mthembu, M. S. (2015). The impact of Education Expenditure, Tertiary Enrolment and Innovation on Economic Growth in South Africa. DSpace/Manakin Faculty of Commerce, Administration and Law. URI: http://hdl.handle.net/10530/1374 
Mueller, M. (2000). Technology and institutional innovation: internet domain names. International Journal of Communications Law and Policy, Issue 5. https://ciaotest.cc.columbia.edu/olj/ijclp/ijclp_5/ijclp_5a.pdf

Murad, W., Alam, M., Noman, A. H. \& Ozturk, I. (2018). Dynamics of technological innovation, energy consumption, energy price and economic growth in Denmark, Environmental Progress \& Sustainable Energy. https://doi.org/10.1002/ep.12905. https://aiche.onlinelibrary.wiley.com/doi/abs/10.1002/ep.12905

Nadiri, M. I. \& Prucha, I. R. (1996). Estimation of the depreciation rate of physical and R\&D capital in the US total manufacturing sector https://doi.org/10.1111/j.1465-7295.1996.tb01363.x

Nagaoka, S., Motohashi, K. \& Goto, A. (2010). Patent Statistics as an Innovation Indicator. In Handbook of the Economics of Innovation,NorthHolland,volume 2, pp. 1083-1127, ISSN 2210-8807, ISBN 9780444536099. https://doi.org/10.1016/S0169-7218(10)02009-5. (https://www.sciencedirect.com/science/article/pii/S0169721810020095)

Nardo, M., Saisana, M., Saltelli, A. \& Tarantola, S. (2005). Tools for Composite Indicators Building. Joint Research Centre. European Commission - Itália. http://citeseerx.ist.psu.edu/viewdoc/download?doi=10.1.1.958.2519\&rep=rep1\&type=pdf

Nelson, R. R. \& Winter, S. G. (1982). Uma teoria evolucionária da mudança econômica. http://inctpped.ie.ufrj.br/spiderweb/pdf_2/Dosi_1_An_evolutionary_ theory-of_economic_change..pdf

Newman, A., Schwarz, S. \& Borgia, D. (2014). How does microfinance enhance entrepreneurial outcomes in emerging economies? The mediating mechanisms of psychological and social capital. International Small Business Journal: Researching Entrepreneurship, Volume: 32, (2), pp.(s): 158-179. https://doi.org/10.1177/0266242613485611

OECD Scoreboard, (2013). STI Scoreboard 2013 interactive charts. https://www.oecd.org/sti/scoreboard-2013-interactivecharts.htm\#: :text=The\%20260\%20indicators\%20in\%20the\%20OECD\%20Science\%2C\%20Technology,policies\%20and\%20monitor\%20progress\%20toward s\%20their\%20desired\%20goals.

OECD (2010). Taxation, innovation and the environment. Paris, France: OECD. https://www.oecd-ilibrary.org/deliver/9789264087651-1fr.pdf?itemId=/content/component/9789264087651-1-fr\&mimeType=application/pdf

Oliveira, J. B. \& Filion, L. J. (2008). Modelo sinérgico de pesquisa subsidiada: transferência de tecnologia, criação de empresas e inovação. INMR Innovation \& Management Review, 5(1), 53-66. https://www.revistas.usp.br/rai/article/view/79100

Oliveira, R. C. (2002). Avaliação do Desempenho Logístico. REAd - Revista Eletrônica de Administração, v. 8 (1). Escola de Administração | Universidade Federal do Rio Grande do Sul, https://www.seer.ufrgs.br/read/article/view/46498/28976

Oluwatobi, S., Efobi, U., Olurinola, I. \& Alege, P. (2014). Innovation in Africa: Why Institutions Matter. South African Journal of Economics - SAJE. https://doi.org/10.1111/saje.12071

Olvido, M. M. \& Sanchez, J. M. (2017). Government Spending vis-à-vis Business Enterprise Investments on Research and Development. CNU Journal of Higher Education, volume 11, pp. 13-23. https://www.researchgate.net/publication/325922671_Government_Spending_vis-avis_Business_Enterprise_Investments_on_Research_and_Development

Omar, N.S. (2019), "Innovation and economic performance in MENA region". Review of Economics and Political Science, Vol. 4 (2), pp. 158-175. https://doi.org/10.1108/REPS-12-2018-0042

O’Neale, D. R. J. e Hendy, S. C. (2012). Power Law Distributions of Patents as Indicators of Innovation. PLoS ONE 7(12): e49501. https://doi.org/10.1371/journal.pone.0049501

Oslo Manual (2018). The measurement of scientific and technological activities. Proposed guidelines for collecting and interpreting technological innovation data. Organisation for Economic Co-operation and Development - OECD. https://www.oecd.org/science/inno/2367614.pdf

Pavitt, K. (1985). Patent statistics as indicators of innovative activities: Possibilities and problems. Scientometrics, volume 7 (1-2), pp. 77-99. DOI: https://doi.org/10.1007/bf02020142. https://akjournals.com/view/journals/11192/7/1-2/article-p77.xml

Pegkas, P., Staikouras, C. \& Tsamadias, C. (2019) Does research and development expenditure impact innovation? Evidence from the European Union countries. Journal of Policy Modeling, Volume 41 (5), pp. 1005-1025, ISSN 0161-8938. https://doi.org/10.1016/j.jpolmod.2019.07.001. (https://www.sciencedirect.com/science/article/pii/S0161893819300869)

Pelikánová, R. M. (2019). R\&D Expenditure and Innovation in the EU and Selected Member States. Fundacja Upowszechniajaca Wiedze i Naukę "Cognitione". Journal of Entrepreneurship, Management and Innovation. Issue Year: 15/2019 (1), pp. Range: 13-34. https://www.ceeol.com/search/articledetail?id=758886

Pereira, D. M. \& Silva, G. S. (2010). As Tecnologias de Informação e Comunicação (TICs) como aliadas para o desenvolvimento. Cadernos de Ciências Sociais Aplicadas n. 10 151-174. https://core.ac.uk/download/pdf/236652502.pdf

Pesole, A. (2015). How much does ICT contribute to innovation output? An analysis of the ICT component in the innovation output indicator. JRC Working Papers JRC94372, Joint Research Centre. https://ideas.repec.org/p/ipt/iptwpa/jrc94372.html

Powers, J. B. \& McDougall, P. P. (2005). University start-up formation and technology licensing with firms that go public: a resource-based view of academic entrepreneurship. Journal of Business Venturing, Volume 20 (3), pp. 291-311. ISSN 0883-9026. https://doi.org/10.1016/j.jb\&svent.2003.12.008. (https://www.sciencedirect.com/science/article/pii/S0883902604000291) 
Pradhan, R. P., Arvin, M. B., Hall, J. H. \& Nair, M. (2016). Innovation, financial development and economic growth in Eurozone countries. Applied $\begin{array}{lllll}\text { Economics } & \text { Letters, } & \text { 23:16, } & 1141-1144 . & \text { DOI: }\end{array}$ https://www.tandfonline.com/action/showCitFormats?doi=10.1080\%2F13504851.2016.1139668

Preenen, P. T., Vergeer, R. \& Kraan, K. (2015). Labour productivity and innovation performance: The importance of internal labour flexibility practices. Sage Journals. https://doi.org/10.1177/0143831X15572836

Quacquarelli Symonds - QS. (2020). World University Ranking 2019/2020). QS Quacquarelli Symonds Ltd, QS World University Ranking 2019/2020, Top Universities. (https://www.topuniversities.com/qs-world-university-rankings).

Queiroz, S. \& Carvalho, R. Q. (2005). Empresas multinacionais e inovação tecnológica no Brasil. São Paulo em Perspectiva [online]. V. 19 (2), pp. 51-59. ISSN 1806-9452. https://doi.org/10.1590/S0102-88392005000200005.

Radionova, I. \& Boger, O. (2014). Тах Burden and Innovation Activities: the interrelation problem. Јоurnal: Економічний часопис - XXI, Issue No: 0102(1), pp. 65-69. https://www.ceeol.com/search/article-detail?id=275083

Ramos, M. N. (2010). Educação de qualidade e sua relação com C\&T e inovação, Ed. Esp. v. 15, n. 31, p. 27-42, jul-dez. Brasília-DF. http://seer.cgee.org.br/index.php/parcerias_estrategicas/article/view/586/552

Rapini, M. (2009). Sistemas financeiros cofinanciamento à inovação: algumas reflexões para o Brasil. Textos Para Discussão Cedeplar-UFMG. https://www.academia.edu/26673070/Sistemas_financeiros_eo_financiamento_\%C3\%A0_inova\%C3\%A7\%C3\%A3o_algumas_reflex\%C3\%B5es_para_o_Br asil?auto=citations\&from=cover_pp.

Reuvers, M., Engen, M. L. V., Vinkenburg, C. J. \& Wilson-Evered, E. (2008). Transformational Leadership and Innovative Work Behaviour: Exploring the Relevance of Gender Differences. Creativity and Innovation Management, volume17(3), pp. 227-244. https://doi.org/10.1111/j.1467-8691.2008.00487.x

Rocha, E. M. P. \& Ferreira, M. A. T. (2004). Indicadores de ciência, tecnologia e inovação: mensuração dos sistemas de CTeI nos estados brasileiros. Ciência da Informação. ISSN 0100-1965 On-line version ISSN 1518-8353 Ci. Inf. vol.33 (3), Brasília Sept./Dec. 2004. https://doi.org/10.1590/S010019652004000300008

Rodrick, D. (2004) "Industrial Policy for the 21st Century". CEPR, Documento para reflexão 4767. SSRN Electronic Journal. DOI: 10.2139/ssrn.617544 file://C:/Users/aldem/AppData/Local/Packages/Microsoft.MicrosoftEdge_8wekyb3d8bbwe/TempState/Downloads/SSRN-id617544.pdf

Rodríguez-Pose, A. \& Di Cataldo , M. (2015). Quality of government and innovative performance in the regions of Europe. Journal of Economic Geography, Volume 15(4), July 2015, pp. 673-706, https://doi.org/10.1093/jeg/lbu023

Rodríguez-Pose, A. \& Zhang, M. (2020). The cost of weak institutions for innovation in China. Technological Forecasting and Social Change, Volume 153, 119937. ISSN 0040-1625, https://doi.org/10.1016/j.techfore.2020.119937. (https://www.sciencedirect.com/science/article/pii/S004016251932030X)

Roman, A. R. \& Friedlander, M. R. (1998). Revisão integrativa de pesquisa aplicada à enfermagem. Cogitare Enferm. 1998;3(2), pp.109-12. https://pesquisa.bvsalud.org/portal/resource/pt/lil-350514

Saltane, V., Chen, R. \& Guzman, N. M. (2013). Measureable Results! Doing Business Project Encourages Economies to Reform Insolvency Frameworks. IFC smart lessons brief,. World Bank. https://openknowledge.worldbank.org/handle/10986/17042.

Saisana, M. (2004). Composite Indicators - A review. Second Workshop on Composite Indicators os Country Performance. OECE, Paris. https://www.researchgate.net/profile/Michaela-Saisana/publication/267986167_Composite_Indicators_-

_A_review/links/554b77e10cf21ed213594143/Composite-Indicators-A-review.pdf

Samoilikova, A. (2020). Financial Policy of Innovation Development Providing: The Impact Formalization. Financial Markets, Institutions and Risks, 4(2),pp. 5-15. https://doi.org/10.21272/fmir.4(2).5-15.2020. https://armgpublishing.sumdu.edu.ua/journals/fmir/volume-4-issue-2/article-1/

Sampat, B. N. (2018) A Survey of Empirical Evidence on Patents and Innovation. NBER Working Paper No. 25383. December 2018. JEL No. O34. https://www.nber.org/system/files/working_papers/w25383/w25383.pdf

Sandu, S. \& Ciocanel, B. (2014) Impact of R\&D and Innovation on High-tech Export. Procedia Economics and Finance, Volume 15, 2014, pp. 80-90. ISSN 2212-5671, https://doi.org/10.1016/S2212-5671(14)00450-X. (https://www.sciencedirect.com/science/article/pii/S221256711400450X).

Sandven, T, Smith, K. H. \& Kaloudis, A. (2005). Structural change, growth and innovation: the roles of medium and low-tech industries, 1980-2000', in Hartmut Hirsch-Kreinsen and David Jacobson and Staffan Laestadius (eds.), Low-tech Innovation in the Knowledge Economy, Peter Lang, Frankfurt, Germany, pp. 31-59. https://eprints.utas.edu.au/1424/

Satrovic, E., Muslija, A., Abul, S. J., Gligoric, D. \& Dalwai, T. (2021). Interdependence between Gross Capital Formation, Public Expenditure on R\&D and Innovation in Turkey. Journal of Balkan and Near Eastern Studies, v. 23 (1), 163-179, DOI: 10.1080/19448953.2020.1818027.

Schumpeter, J. A. (1997). Teoria do desenvolvimento econômico Uma investigação sobre lucros, capital, crédito, juro e o ciclo econômico. http://www.ufjf.br/oliveira_junior/files/2009/06/s_Schumpeter_-_Teoria_do_Desenvolvimento_Econômico_-

_Uma_Investigação_sobre_Lucros_Capital_Crédito_Juro_e_Ciclo_Econômico.pdf. 02/01/2018.

Siekierski, P. (2018). Relação entre mobilidade acadêmica internacional e inovação: impactos nos países de origem e destino dos pesquisadores. Tese: Programa de Doutorado em Administração com Concentração em Gestão Internacional - Escola Superior de Propaganda e Marketing, São Paulo. http://tede2.espm.br/handle/tede/290

Siekierski, P., Lima, M. C. \& Borini, F. M. (2019). Mobilidade acadêmica internacional e depósito de patentes no país de origem. Rev. Adm. Pública, v. 53 (3). Rio de Janeiro May/June 2019. https://doi.org/10.1590/0034-761220170378 
Siqueira Neto, A. S., Barcelos, M. T. C. \& Danilo de Melo Costa, D. M. (2018). Perspectivas e percepções da inovação no mercado dos aplicativos bancários. Desafio Online v.6 (1), pp. 25-42, ESAN/UFMS. http://www.desafioonline.ufms.br

Simas, M. \& Pacca, S. (2013). Energia eólica, geração de empregos e desenvolvimento sustentável. Estudos Avançados. Print version ISSN 0103-4014. Estud. av. v.27(77). São Paulo. https://doi.org/10.1590/S0103-40142013000100008. https://www.scielo.br/pdf/ea/v27n77/v27n77a08.pdf

Soto-Acosta, P. \& Cegarra-Navarro, J.-G. (2016). New ICTs for Knowledge Management in Organizations. Journal of Knowledge Management, v. 20 (3), pp. 417-422. https://doi.org/10.1108/JKM-02-2016-0057

Stepanova, E. V. (2019). Evaluation of innovation potential in Russian clusters. Earth and Environmental Science, v. 315 (2). https://iopscience.iop.org/article/10.1088/1755-1315/315/2/022091/meta

Stern, D. I. (2004). Energy and economic growth, Encyclopedia of Energy, v. 2, Elsevier.http://www.sterndavidi.com/Publications/Growth.pdf

Sternitzke, C. (2009). Defining triadic patent families as a measure of technological strength. Scientometrics, v. 81 (1), pp. 91-109. DOI https://doi.org/10.1007/s11192-009-1836-6. https://akjournals.com/view/journals/11192/81/1/article-p91.xml

Symeonidis, G. (1996). Innovation, Firm Size and Market Structure Schumpeterian Hypotheses and Some New Themes. London School of Economics. Economics Department, Working papers, no. 161. https://www.oecd-ilibrary.org/economics/innovation-firm-size-and-market-structure_603802238336,

Suthersanen, U. (2019). Utility models: do they really serve national innovation strategies? Monograph Chapter, pp. 2-24. Collection: Law 2019. DOI https://doi.org/10.4337/9781789902358.00010

Terziovski, M. \& Guerrero, J-L. (2014). ISO 9000 quality system certification and its impact on product and process innovation performance. International Journal of $\quad$ Production $\quad$ Economics,v.158, pp. $197-207$. https://doi.org/10.1016/j.ijpe.2014.08.011.(https://www.sciencedirect.com/science/article/pii/S0925527314002692).

Theyel, G. (2000). Management practices for environmental innovation and performance. International Journal of Operations \& Production Management, v. 20(2), pp. 249-266. https://doi.org/10.1108/01443570010304288

Thompson, V. A., (1965) - Bureaucracy and Innovation. Administrative Science Quarterly, v. 10 (1), pp. 1-20. https://www.jstor.org/stable/2391646.

Tolbert, C. J., Mossberger, K. \& McNeal, R. (2008). Institutions, Policy Innovation, and E-Government in the American States. Public Administration Review. https://doi.org/10.1111/j.1540-6210.2008.00890.x

Tomás, V. (2011). National Competitiveness and Expenditure on Education, Research and Development. Journal of Competitiveness, Zlin. V. 3 (2). https://www.cjournal.cz/files/53.pdf

Tsaurai, K. (2015). Does human capital development matter in FDI location decisions? A case for Austria. Risk Gov. Control: Fin. Mark. Inst., 5 (3), 26-35. https://doi.org/10.22495/rgcv5i3art3

Van Ark, B. \& Piatkowski, M. (2004). Productivity, innovation and ICT in Old and New Europe. International Economics and Economic Policy 1, pp. 215246. https://doi.org/10.1007/s10368-004-0012-y

Van Rooij, A. (2014). University Knowledge Production and Innovation: Getting a Grip. Minerva 52, pp. 263-272. https://doi.org/10.1007/s11024-014-92541. https://link.springer.com/article/10.1007\%2Fs11024-014-9254-1

Vieira, E, Neira, I. \& Vázquez, E. (2011). Productivity and innovation economy: comparative analysis of european nuts ii, 1995-2004. Regional Studies, 45:9, 1269-1286. DOI: 10.1080/00343404.2010.486781, http://citeseerx.ist.psu.edu/viewdoc/download?doi=10.1.1.224.6746\&rep=rep1\&type=pdf

Vincent-Lancein, S. (2004). Building Capacity through Cross-border Tertiary Education. OECD, 11 e 12/10/2004, Sidney/Austrália. https://www.ceintelligence.com/files/documents/Tertiary\%20Education\%20SVLancrin.pdf

Vivaldi, G. A. D., Portugal Júnior, S. \& Camarini, G. (2021). Propriedade intelectual, inovação e crescimento econômico: uma análise estatística nas microrregiões do Sul de Minas Gerais. Revista Brasileira de Desenvolvimento Regional, Blumenau, v. 9 (2), pp. 85-106. ISSN 2317-5443. https://bu.furb.br/ojs/index.php/rbdr/article/view/8858.

Wachowska, M. (2018). Consequences of the Post-Accession Migration of Polish Inventors for the Innovative Potential of Poland: 2004-2012. Fundacja Centrum Badań Socjologicznych. Issue 1, pp.: 311-324. https://www.ceeol.com/search/article-detail?id=719229.

Wang, C., Rodan, S., Fruin, M. \& Xu, X. (2013) Knowledge Networks, Collaboration Networks, and Exploratory Innovation. Academy of Management Journal, v. 57 (2). https://doi.org/10.5465/amj.2011.0917.

Wang, Y., Jiang, W. \& Li, X. (2010). The study on the appraisal of influencing factors of the enterprise technology innovation talents' team. International Conference on Future Information Technology and Management Engineering, pp. 252-255. Doi: 10.1109/FITME.2010.5654905. https://ieeexplore.ieee.org/abstract/document/5654905

Wen, J., Deng, P., Zhang, Q. \& Chang, C.-P. (2021). Is higher government efficiency bringing about higher innovation?. Technological and Economic Development of Economy, 1-30. https://doi.org/10.3846/tede.2021.14269

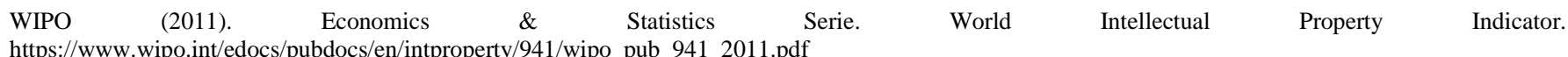

Xiaohua, S., Yun, W. \& Ran X. (2015). Financial development, financing restriction ease and firm R\&D investments, Science Research Management, v. 36(5), pp. 47-54.https://link.springer.com/article/10.1007/s10690-019-09273-5 
Research, Society and Development, v. 11, n. 3, e19911326092, 2022

(CC BY 4.0) | ISSN 2525-3409 | DOI: http://dx.doi.org/10.33448/rsd-v11i3.26092

Yoon, E. \& Tello, S. (2009). Corporate Social Responsibility as a Driver of Sustainable Innovation: Greening Initiatives of Leading Global Brands. Scholarly Journals. Competition Forum, Indiana, v. 7 (2), pp. 290-294. https://www.proquest.com/docview/214846053?pq-origsite=gscholar\&fromopenview=true

Zajac, E. J., Golden, B. R. \& Shortell, S. M. (1991). New Organizational Forms for Enhancing Innovation: The Case of Internal Corporate Joint Ventures. Management Science, v. 37 (2). https://doi.org/10.1287/mnsc.37.2.170

Zosa, V. H. (2013). The Entrepreneurial University: The Building Block of the Innovation Economy. International Peer Reviewed Journal, Vol. 6 January 2013, Print ISSN 2244-1492 • online ISSN 2244-1506. https://www.researchgate.net/profile/EmanuelKristijadi/publication/304485765_Management_of_Credit_Activities_and_their_Effects_on_Commercial_Banks\%27_Credit_Risk_in_Indonesia/links/5a7dc3

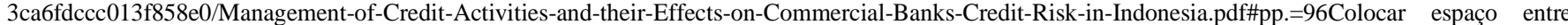
uma referência e outra. 